MARKET STRUCTURE AND EXTORTION:

EVIDENCE FROM 50,000 EXTORTION PAYMENTS

Zach Y. Brown

Eduardo Montero

Carlos Schmidt-Padilla

Maria Micaela Sviatschi

WORKING PAPER 28299 
NBER WORKING PAPER SERIES

\title{
MARKET STRUCTURE AND EXTORTION: EVIDENCE FROM 50,000 EXTORTION PAYMENTS
}

\author{
Zach Y. Brown \\ Eduardo Montero \\ Carlos Schmidt-Padilla \\ Maria Micaela Sviatschi \\ Working Paper 28299 \\ http://www.nber.org/papers/w28299
NATIONAL BUREAU OF ECONOMIC RESEARCH
1050 Massachusetts Avenue \\ Cambridge, MA 02138 \\ December 2020, Revised February 2023
}

We are grateful to Lauren Falcao Bergquist, Chris Blattman, Doris Chiang, Abby Córdova, Rafael Di Tella, Oeindrila Dube, Thomas Fujiwara, Sergio Galletta, Robert Gibbons, Rema Hanna, Benjamin Lessing, Nicola Limodio, Alex Mas, Mike Mueller-Smith, Nathan Nunn, Rohini Pande, Alison Post, Jake Shapiro, Andrei Shleifer, Vincent Tanutama, Santiago Tobón, and seminar participants at Berkeley, BREAD 2021, Columbia, Erasmus University Rotterdam, Harvard Business School, LANE-HOPE, Michigan, NEUDC 2021, Notre Dame, PacDev 2021, Paris Sorbonne, Princeton University, SIOE, Stanford, Texas A\&M, TWEC 2022, Universidad de Costa Rica, Universidad EAFIT, University of Gothenburg, University of North Carolina, University of Wisconsin, University of Zurich, Queen's University, and Yale. We thank Rachel Fung, Pedro Magana, Paulo Matos, and Carolina Tojal Ramos dos Santos for excellent research assistance. The views expressed herein are those of the authors and do not necessarily reflect the views of the National Bureau of Economic Research.

NBER working papers are circulated for discussion and comment purposes. They have not been peer-reviewed or been subject to the review by the NBER Board of Directors that accompanies official NBER publications.

(C) 2020 by Zach Y. Brown, Eduardo Montero, Carlos Schmidt-Padilla, and Maria Micaela Sviatschi. All rights reserved. Short sections of text, not to exceed two paragraphs, may be quoted without explicit permission provided that full credit, including @ notice, is given to the source. 
Market Structure and Extortion: Evidence from 50,000 Extortion Payments

Zach Y. Brown, Eduardo Montero, Carlos Schmidt-Padilla, and Maria Micaela Sviatschi

NBER Working Paper No. 28299

December 2020, Revised February 2023

JEL No. D74,K42,L10,O17

\section{ABSTRACT}

How does gang competition affect extortion? Using detailed data on individual extortion payments to gangs and sales from a leading wholesale distributor of consumer goods and pharmaceuticals in El Salvador, we document evidence on the determinants of extortion payments and the effects of extortion on firms and consumers. We exploit a 2016 nonaggression pact between gangs to examine how collusion affects extortion in areas where gangs previously competed. While the pact led to a large reduction in competition and violence, we find that it increased the amount paid in extortion by approximately $20 \%$. Much of this increase was passed through to retailers and consumers: retailers experienced an increase in delivery fees, leading to an increase in consumer prices. In particular, we find an increase in prices for pharmaceutical drugs and a corresponding increase in hospital visits for chronic illnesses. The results point to an unintended consequence of policies that reduce competition between criminal organizations.

Zach Y. Brown

Department of Economics

University of Michigan

611 Tappan Ave

Ann Arbor, MI 48109

and NBER

zachb@umich.edu

Eduardo Montero

Harris School of Public Policy

University of Chicago

1307 E 60th St

Chicago, IL 60637

and NBER

emontero@uchicago.edu
Carlos Schmidt-Padilla

Stanford University

616 Serra Mall

Encina Hall

Stanford, CA 94305-6055

cschmidtpadilla@gmail.com

Maria Micaela Sviatschi

Department of Economics

Princeton University

128 Julis Romo Rabinowitz

Princeton, NJ 08544

and NBER

msviatschi@princeton.edu 


\section{Introduction}

Organized crime and the extortion associated with it are pervasive aspects of life in many countries. Because extortion is often a main revenue source for organized crime, it often drives competition and violence between gangs worldwide (Konrad and Skaperdas 1998; Global Initiative Against Transnational Organized Crime 2019). Extortion can be a significant cost for firms and may have implications for consumer prices in countries with criminal organizations. Despite the prevalence of extortion in weak states, it is rarely reported to the police and is difficult to measure systematically. Due to the considerable challenges of measuring extortion, little is known about how gangs determine extortion rates, how competition between gangs for territory affects extortion, and what the resulting economic effects of extortion are.

It is particularly important to understand how gang truces affect extortion. Controversial pacts or truces between gangs have been brokered by governments, religious leaders, aid workers, or gangs themselves in numerous countries, including El Salvador, Honduras, Haiti, Brazil, South Africa, Trinidad and Tobago, Japan, and Jamaica (Kan 2014; Cockayne et al. 2017). While these truces often lead to an immediate reduction in violence, it has been argued that they could allow gangs to grow stronger. It is unclear how gang truces affect extortion. On one hand, they may lead to a decrease in extortion if extortion is primarily used to finance confrontations for territory. ${ }^{1}$ On the other hand, truces could be viewed as a collusive agreement, allowing gangs to shift resources away from fighting rivals and toward collecting extortion.

In this paper, we exploit a 2016 nonaggression pact between gangs in El Salvador to provide causal evidence on how gang collusion affects extortion, and to document the downstream effects of extortion on firms and consumers. In El Salvador, as in much of northern Central America, upwards of $70 \%$ of businesses in gang-controlled territories report being extorted by gangs (Martínez et al. 2016). We leverage unique administrative data on individual extortion payments combined with detailed sales data for all goods shipped by a major Salvadoran wholesale distributor of consumer goods and pharmaceutical drugs. The data have information on over 50,000 extortion payments in which truck drivers were stopped by gangs while making deliveries to over 36,000 unique retailers between 2012 and 2019. Using these data, we show that collusion between gangs increased the average amount paid in extortion. We further show that firms respond by passing the increase in extortion through to retailers, which increases prices for consumers. These results provide new evidence on

\footnotetext{
${ }^{1}$ Also, stability in territory may lead to less short-term extraction by gangs and thereby reduce extortion. This closely follows the arguments of Olson (1993) and Tilly (2017).
} 
consequences of gang truces for firms and consumers.

We start with a simple theoretical framework to highlight the role of competition and price discrimination in the market for extortion. The model combines insights from the literature on competition and conflict between gangs (e.g., Garfinkel and Skaperdas 2007; Castillo and Kronick 2020) with the industrial organization literature on vertical markets with market power (e.g., Spengler 1950). In the model, each gang has an incentive to use violence to expand their territory and collect additional extortion. However, gangs can realize higher profits if they can collude and agree not to compete for territory. This allows the gangs to act as monopolists and shift resources to collecting extortion. The model implies that collusion between gangs decreases violence and shows conditions under which this increases extortion and downstream prices. Furthermore, the model provides insight into how gangs may set the amount of extortion payments and price-discriminate.

We then use the distributor data to provide a descriptive analysis of the main correlates of extortion. We find that extortion is higher when the value of products being delivered is higher, consistent with price discrimination. We also show cross-sectional evidence that competition between gangs is associated with higher extortion amounts. However, competition is endogenous, given that gangs are likely to compete over territories with larger returns from extortion.

To provide causal estimates on the effect of gang collusion, we focus on the March 2016 pact, in which the two gangs in El Salvador agreed to respect each other's existing territory rather than compete for it. This resulted in a large reduction in violent competition, lowering the homicide rate in El Salvador by nearly half. We examine the effect of the pact in municipalities in which gangs previously competed compared to areas in which a gang already had a monopoly or near monopoly on territory. In our primary analysis, we define our control group as areas where only one gang was committing nearly all homicides-these areas were unaffected by the pact. We also show results that are robust to alternative definitions of gang competition prior to the pact, including measures constructed from prison records.

The pact increased the amount paid in extortion by $20 \%$ to $25 \%$ in areas with previous gang competition relative to control areas. The results are especially pronounced in areas with high development-these areas see an increase in extortion of $35 \%$. We show that these results are robust to accounting for other government policies aimed at reducing the power of gangs. We also find evidence that gangs increased their threats of violence after the pact. This is consistent with both qualitative accounts and the theoretical framework highlighting that the pact may have allowed the gangs to focus on collecting extortion.

We then provide evidence on how firms respond to the resulting higher extortion pay- 
ments. We find no evidence that the firm adjusts its deliveries, consistent with the fact that the firm has long-standing relationships to supply retailers. However, the distributor does adjust wholesale prices in response to extortion and the pass-through is substantial. The increase in extortion raises the wholesale costs for the nearest retailer by $12 \%$. The costs for retailers farther from the location of extortion payments also increases, but by less. We also find support for the theoretical prediction that prices increase most for goods with inelastic demand, such as staple food products, suggesting that the increase in extortion may disproportionately impact poorer households. Finally, we use detailed data on retail prices for pharmaceutical drugs to examine the downstream effect for consumers. The pact increased retail prices for drugs by $8 \%$. We then examine hospital visits and find that for chronic diagnoses potentially affected by drug adherence, visits increase by $9 \%$.

Our results have several implications. First, our case study helps illuminate how extortion affects firms and consumers. Our results highlight that certain goods-namely those with inelastic demand, such as staple products and pharmaceutical drugs-are particularly affected by extortion. This finding provides insights into who bears the cost of extortion and which goods are particularly lucrative targets for gangs. Second, while truces often generate a short-run decline in violence, the countervailing cost imposed by higher extortion may allow criminal organizations to become more entrenched. Given the prevalence of gang truces, this finding has implications for understanding gangs in a variety of countries. Finally, our results are relevant for settings outside Central America. The two main gangs we study, MS-13 and Barrio 18, are present throughout Central America, Mexico, Spain, and the United States. Gang violence and extortion have led millions of refugees to migrate from El Salvador, Guatemala, and Honduras toward developed countries (Sviatschi 2018; Clemens 2021). Thus, policies that inadvertently increase extortion and consumer prices may have important policy spillovers for developed countries.

Our study contributes to several strands of the literature. First, we contribute to the literature on the consequences of organized crime. Several papers examine the effect of gangs on economic development via their impact on human capital accumulation, labor markets, and state capacity (Angrist and Kugler 2008; Sviatschi 2018; Melnikov et al. 2020; Blattman et al. 2021). Our study highlights an additional mechanism: the distortionary effects of extortion on downstream firms and consumers. We show how an increase in extortion is passed through to firms and consumers. This is especially important for the case of pharmaceutical drugs, where there are significant concerns about affordability and efficient supply chains (Seiter 2010; Yamagiwa 2015).

Second, our study is related to the broader literature on the economics of illicit mar- 
kets. One influential subset focuses on the market for government corruption (e.g., Shleifer and Vishny 1993; Bliss and Di Tella 1997; Ades and Di Tella 1999; Olken and Barron 2009; Amodio et al. 2021; Foltz and Li 2021). Shleifer and Vishny (1993) argue theoretically that corrupt officials should be thought of as profit-maximizing agents and point out that competition between government officials can reduce bribery. Olken and Barron (2009) empirically highlight the role of market structure in government bribes at checkpoints; they find that the payment amount depends on the number of checkpoints. A related strand of this literature studies competition between criminal organizations in illicit drug markets (e.g., Levitt and Venkatesh 2000; Dell 2015; Castillo and Kronick 2020; Bruhn 2021). However, despite extortion being a key revenue source for organized gangs worldwide, there is little work studying the market for it or how gangs compete for it. Previous work relies on self-reported data on whether individuals have paid extortion (FUSADES 2016; Magaloni et al. 2020b). We leverage unique administrative panel data on individual extortion payments from a large wholesale distribution firm to provide evidence on the determinants of extortion and on the causal effect of collusion between gangs.

Finally, our work speaks to the broader industrial organization literature on collusive agreements between firms. Firms may use violence or threats of violence to enforce collusion or deter entry when incumbents collude (e.g., Clark and Houde 2013; Clark et al. 2018). A growing literature examines issues related to collusion and competition in developing countries (Houde et al. 2022; Bergquist and Dinerstein 2020). We provide new empirical evidence on collusion in an illegal market where gangs compete for territory. Unlike collusion in standard settings, collusion between criminal organizations reduces violence, allowing gangs to increase the amount they collect in extortion.

The remainder of the paper is organized as follows. Section 2 provides background information on gangs and extortion in El Salvador, and describes the distributor's sales and extortion data. Section 3 presents the theoretical framework. Section 4 provides a descriptive analysis of the main determinants of extortion. Section 5 presents the estimates of the pact on extortion. Section 6 presents the pass-through estimates. Section 7 presents the effects on pharmaceutical prices and hospital visits. Section 8 concludes.

\section{Background, Institutional Setting, and Data Sources}

In this section, we provide background information on gang violence and extortion in El Salvador and describe the 2016 nonaggression pact. We present details on the wholesale distributor that provided us with sales and extortion data, and we describe additional data 
sources we use in the subsequent analysis.

\subsection{Gang Violence, Extortion, and Collusion in El Salvador}

With a murder rate of 103 per 100,000 inhabitants - the highest murder rate worldwide in 2015-El Salvador has become known as one of the most violent peacetime countries in the world (Gagne 2016). This violence is largely driven by the fact that two gangs, Mara Salvatrucha (MS-13) and Barrio 18, fight for territory to extort firms (Papadovassilakis and Dudley 2020). ${ }^{2}$ These two gangs account for $87 \%$ of gang membership and are estimated to have over 60,000 members and a support base equal to $8 \%$ of El Salvador's population (Aguilar et al. 2006, ICG 2017b).

Criminal organizations often use protection rackets, in which they offer firms security in exchange for a fee. The gangs in El Salvador primarily rely on extortion, in which they collect payment under the threat of violence. Extortion is often considered a type of protection racket in which the threat of violence comes primarily from the group offering the protection. Extortion represents the largest share of gang income: it is described as the "economic engine" behind the gangs and violence (ICG 2017a). ${ }^{3}$ A majority of businesses in El Salvador pay extortion to gangs, with distribution and transport firms being particularly affected (Martínez et al. 2016). Extortion differs from bribes to government officials, given that bribes provide access to a good or service and have ambiguous efficiency effects (Shleifer and Vishny 1993). In contrast, the negative effects of extortion and associated violence are less ambiguous. The Salvadoran central bank estimates the direct and indirect costs of gangs to be as much as $16 \%$ of GDP (Peñate Guerra et al. 2016).

To address the gang problem, the Salvadoran government has alternated between violent confrontations and direct negotiations with gangs (ICG 2017a; Holland 2013). Most prominently, it negotiated a controversial truce between the two main gangs in March 2012. The immediate effect was less violence- the homicide rate fell by more than half in the month following the truce (see Figure 1). The 2012 truce was called off by the government in June 2013 in response to growing opposition within the government and across civil society (Vuković and Rahman 2018). Following the 2014 election, the newly elected government reverted to a policy of violent confrontation, and violence subsequently increased.

On March 26, 2016, the leaders of the main gangs unexpectedly announced a pact that

\footnotetext{
${ }^{2}$ For a discussion of the history of gangs in El Salvador, and the role of deportations, see Sviatschi (2019, 2022). In particular, the United States deported Central American leaders of the two competing gangs from California, generating a rise in violence mainly due to competition for territory in their places of origin.

${ }^{3}$ Gangs in El Salvador also earn revenue from drug-trafficking, but this is thought to be much lower than the revenue from extortion. Gangs in El Salvador do not have direct control over the drug trade; they have only a sporadic "sub-contractual relationship" with drug traffickers (ICG 2017b).
} 
Figure 1

Homicides and Collusion Between Gangs

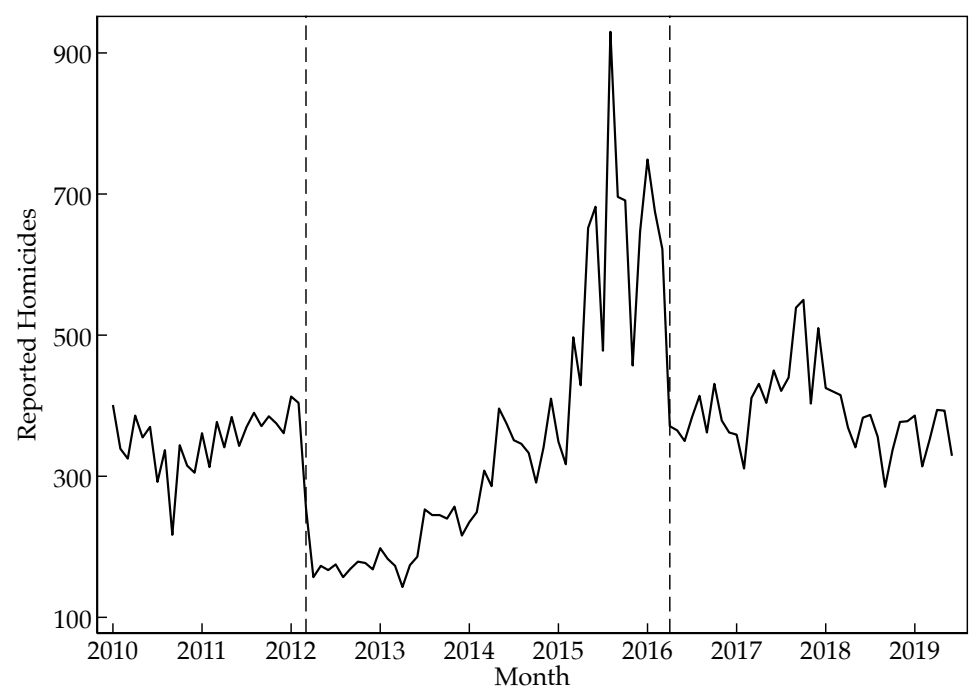

Notes: Chart shows reported homicides in El Salvador by month. Vertical lines show the start of the gang truce (March 2012) and the nonaggression pact (April 2016).

prohibited the invasion of other gangs' territories and violence targeting members of rival gangs (Ditta 2016; Martínez 2016). Unlike the 2012 truce, the 2016 pact was negotiated directly between gang representatives without government intermediaries. However, similar to the 2012 truce, religious leaders played an important role in the negotiations (Martínez 2016). 4 In a manner reminiscent of collusive agreements between firms, the gangs set up a 12-member "coordinating committee" that would meet to maintain exclusive territories (Martínez 2016). As one gang representative detailed: "At present, we have a nonaggression pact between us, the idea being that boundaries will be respected. There are always problems that have to be resolved. It is not perfect. There's always someone that shoots, but that is why we are here" (Martínez 2016). The homicide rate immediately fell by nearly half in the three subsequent months and then stayed relatively constant through 2019 (see Figure 1. Media reports indicate that the pact was still in place as of the end of our sample period (Papadovassilakis 2020).

It is well known that both the 2012 truce and the 2016 pact affected homicides, but did they also affect extortion? Some have argued that cooperation could allow gangs to grow stronger and increase extortion. For instance, Dudley (2013) notes that "one theory [is]

\footnotetext{
4The pact may have also been negotiated in response to increased enforcement measures being debated by the government at the time (Ditta 2016). Importantly for our identification, we do not observe differential changes in violence between treated and control municipalities before the pact.
} 
Figure 2

Geography of Extortion

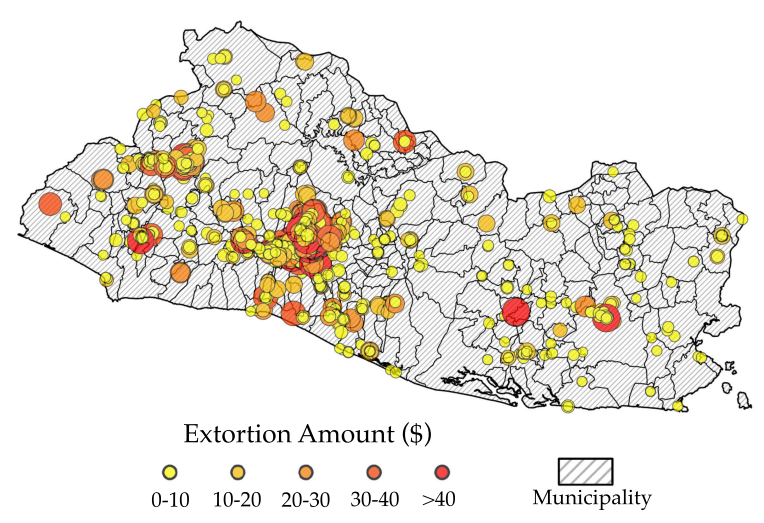

Panel A: El Salvador

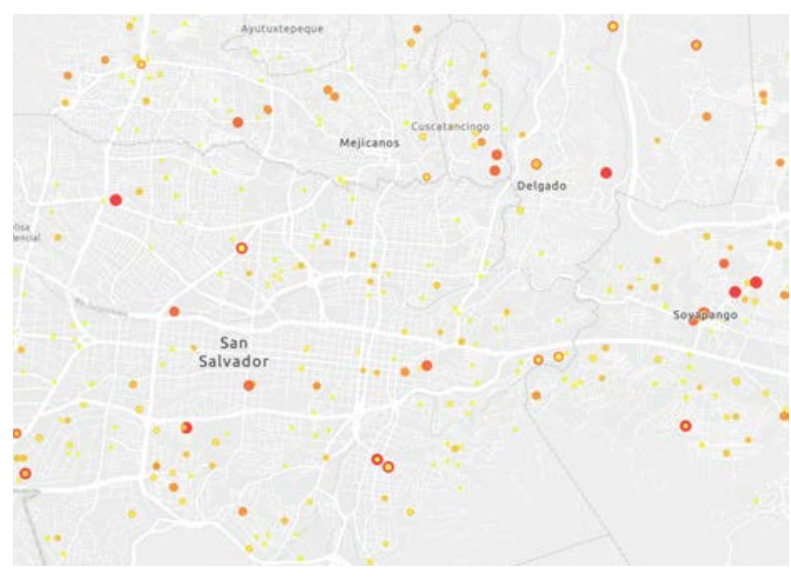

Panel B: Central San Salvador

Notes: These two maps depict the locations of all extortion payments the firm made between March 2012 and March 2019. Points represent extortion payments, and their size corresponds to the amount paid in U.S. dollars, El Salvador's official currency. Panel A shows the entire country, with municipality borders in gray. Panel B shows central San Salvador.

that the gang truce was really an effort by larger criminal interests to grant the MS-13 and Barrio 18 more breathing room for their operations." Collecting extortion requires constant monitoring of trucks and retailers and credibly threatening violence. After the pact, gangs may have been able to focus their resources on collecting extortion (ICG 2020).

\subsection{Extortion and Distributor Sales}

We use extortion payment data and sales data for all goods delivered by a leading wholesale distributor from 2012 through 2019.5 The distributor is a major supplier of consumer goods and pharmaceuticals. It buys these goods in bulk from domestic and international manufacturers and delivers the products to local retailers and pharmacies. Each morning, the firm's trucks leave from San Salvador and make deliveries along one of 450 unique routes that cover the entire country. Over the sample period, the trucks went on 93,387 trips, making 2.2 million deliveries to retailers and pharmacies.

The distributor employs a security team to manage extortion payments, a common approach in the industry. Before making a delivery in gang-controlled territory, truck drivers will stop and meet with a gang representative. At this point, they must call the security team, and the security team confirms the extortion amount with the gang representative.

\footnotetext{
${ }^{5}$ Due to a confidentiality agreement with the firm, we do not name it.
} 
The distributor uses this system to reduce fraudulent claims of payments by drivers. The security team then records the payment amount and where it was paid. ${ }^{6}$ In some cases, the extortion amount is pre-negotiated for a given period, often two months or less. Gangs are known to use violence or confiscate goods when extortion is not paid, but they generally prefer consistent extortion payments over extreme measures that deter trucks from returning to an area in the future. Despite the many reports of gangs attacking truck drivers who do not pay, the distributor noted that it was generally successful at avoiding violent confrontation with the gangs.

In general, gangs have exclusive control of a given territory, so the distributor does not choose which gang to pay when making a delivery. In this way, gangs compete over territory rather than directly compete to provide protection from their rival. Importantly, extortion payments give the distributor rights to deliver to retailers. Trucks are often stopped on side streets near the delivery location rather than on main roads, implying that the trucks can pass through an area without paying extortion if they do not make a delivery. In this way, our setting differs from bribes to government officials at checkpoints which grant firms the right to pass through an area (e.g., Olken and Barron 2009). These features of extortion in El Salvador guide our model in Section 3. We provide more details on the mechanics of extortion and gangs' internal organization in Appendix A.

The data on extortion payments contain the amount and location of each payment made to a gang on each route from March 2012 to March 2019.7 Figure 2 Panel A depicts all the extortion payments recorded by the company's security team during the period-a total of 51,576 payments. $^{8}$ Table I Panel A presents summary statistics for the extortion data for the sample period one year before and after the 2016 pact. Individual extortion payments to the gang vary between $\$ 0.50$ and \$140. Conditional on paying extortion, the average truck pays $\$ 16$ per route per day, equal to roughly half the daily labor cost of a truck driver.

The sales data contain details on what was delivered by each truck over the 2009-2019 period. The unit of observation is a product type delivered to a retailer or pharmacy on a given trip. The data include the revenue for each product delivered, the cost paid by the firm to obtain each product, and the corresponding gross margin for each product deliveredthe difference between the cost paid to acquire the product and the amount charged to the retailer at delivery. The data also include the product name, retailer name, and retailer

\footnotetext{
${ }^{6}$ In addition to using these records for its own accounting, the distributor reports extortion payments to the Attorney General's office.

7Information on extortion is missing for eight months: January, February, April, and May of 2013; April 2014; April 2015; and November and December of 2017. Only two of these months fall into our main period of analysis surrounding the pact. We dropped these two months from our analysis.

${ }^{8}$ Appendix Figure A-2 presents a map of total and average extortion paid by the firm across municipalities.
} 
Table 1

Summary Statistics for Extortion, Sales, Homicides, and Inmates

\begin{tabular}{|c|c|c|c|c|}
\hline & Mean & SD & Min & Max \\
\hline \multicolumn{5}{|l|}{ Panel A: Extortion payments } \\
\hline Extortion payment & 8.10 & 10.62 & 0.50 & 140.0 \\
\hline Total extortion by trip & 15.60 & 19.07 & 1.00 & 290.0 \\
\hline Total extortion by route-month & 127.12 & 129.97 & 1.00 & 745.0 \\
\hline Total observations & \multicolumn{4}{|c|}{50,695} \\
\hline \multicolumn{5}{|c|}{ Panel B: Distributor Sales by Retailer-Product-Trip } \\
\hline Amount charged to retailer & 31 & 369 & 0.0 & 189,276 \\
\hline Cost & 26 & 335 & 0.0 & 187,317 \\
\hline Amount by trip & 3,467 & 9,548 & 0.0 & 357,849 \\
\hline Cost by trip & 2,921 & 8,154 & 0.0 & 293,858 \\
\hline Amount by route-month & 107,362 & 264,033 & 28.8 & $2,773,948$ \\
\hline Cost by route-month & 90,444 & 211,085 & 23.4 & $2,117,466$ \\
\hline Unique products & \multicolumn{4}{|c|}{6,038} \\
\hline Unique retailers & \multicolumn{4}{|c|}{36,020} \\
\hline Total trips & \multicolumn{4}{|c|}{93,387} \\
\hline Total observations & \multicolumn{4}{|c|}{$10,552,876$} \\
\hline \multicolumn{5}{|c|}{ Panel C: Homicides by Municipality-Month } \\
\hline Homicides by MS-13 & 0.69 & 1.26 & 0 & 17 \\
\hline Homicides by Barrio-18 & 0.55 & 1.23 & 0 & 15 \\
\hline Total homicides & 4.06 & 5.63 & 1 & 75 \\
\hline Total observations & \multicolumn{4}{|c|}{2,411} \\
\hline \multicolumn{5}{|l|}{ Panel D: Inmates by Municipality } \\
\hline Inmates from MS-13 & 21.06 & 63.37 & 0 & 607 \\
\hline Inmates from Barrio- 18 & 20.29 & 70.49 & 0 & 1006 \\
\hline Total inmates & 41.37 & 121.25 & 0 & 1613 \\
\hline Total observations & \multicolumn{4}{|c|}{256} \\
\hline
\end{tabular}

Notes: All revenues, costs, and payments are reported in U.S. dollars. Our sample periods are March 2012 through March 2019 for Panel A, and June 2015 through December 2017 for Panels B and C. In Panel B, minimum values are rounded to the nearest ten cents. Panel D reports summary statistics for gang-affiliated inmates arrested between April 2013 and April 2016.

addresses where the product was delivered. Table 1 Panel B presents summary statistics for the sales data. 9

We depict the data set combining sales and extortion payments in Figure A-1, a map of all of the deliveries made by the firm on a single day in 2016. It reveals the vast geographic scope of the firm's operations and the prevalence of extortion payments across El Salvador.

\subsection{Homicides and Incarceration}

To construct measures of gang competition, we use data on homicides and incarceration records. Individual-level homicide data for the years 2010 to 2017 were obtained from El Salvador's National Civil Police (PNC) through a freedom-of-information request. The data

${ }^{9}$ Appendix Figure A-3 presents a map of total and average delivery values across municipalities for the firm's deliveries. The firm delivers to almost all of El Salvador's municipalities. 
include information on the date and location of each homicide recorded by the PNC.

The data also include information on which gang committed the homicide based on their investigation and details such as as gang-related graffiti and tattoos. Determining gang affiliation is critical for the police since they use this information after an arrest to separate prisoners by gang affiliation. For gang-related homicides, the police were able to identify the gang responsible in $75 \%$ of cases. ${ }^{10}$ Table 1 Panel C presents summary statistics for the homicide data aggregated to the municipality-month level for the sample period one year before and after the 2016 pact.

To further validate our measure of competition, we obtained cross-sections of all individuals in prison at the end of 2015 and 2018 from the Ministry of Justice and Public Security. These data include information on general demographics, crimes committed or accused, date of first incarceration, accurate gang affiliation, and municipality and department of birth and residence. We use the sample of gang-affiliated inmates whose date of first incarceration occurred in the three years prior to the 2016 pact. Table I Panel D presents their summary statistics.

\subsection{Pharmacy Sales and Hospital Visits}

To examine the downstream effects of extortion on consumers, we focus on retail prices at pharmacies and health outcomes. Retail pharmacy sales data for the years 2014 to 2017 are from the National Directorate of Medicines (DNM). Due to El Savador's high drug prices relative to comparable countries, the government started collecting sales data from pharmacies in 2014 with the intent of monitoring drug prices and increasing price transparency for consumers. Starting in January 2016, the sales data were collected monthly. Before then, sales data were collected less frequently. We observe sales data for December 2014, March 2015, and August 2015.

The data contain information on quantity and revenue by pharmacy for over 10,000 pharmaceutical products. We discuss the sample of drugs and sample of pharmacies in more depth in Section B.4. Table A-I Panel A presents summary statistics for the pharmacy data for the sample period one year before and after the 2016 pact.

To examine how changes in pharmaceutical prices affect health, we use individual-level data on hospital visits at public health facilities for the years 2012 to 2019 obtained from the Ministry of Health (MINSAL) and the Salvadoran Social Security Institute (ISSS). MINSAL is the main public hospital system and operates 30 hospitals, while ISSS operates 11 hospitals

\footnotetext{
${ }^{10}$ We analyze whether the share of homicides with no gang affiliation per municipality is correlated with our measure of gang competition defined in Section 5 . We find that this correlation is statistically and economically insignificant, with an estimated coefficient of -0.006 ( $P$ value of 0.806$)$.
} 
and covers workers in the formal sector and their dependents. The data do not include information for private hospitals in El Salvador; however, only $5 \%$ of the population has private health insurance and can readily access private hospitals. The data have information on the hospital, municipality, visit date, patient characteristics (age and gender), and ICD-10 diagnosis code. ${ }^{11}$ Table A-1 Panel B presents summary statistics for the hospital-visit data for the sample period one year before and after the 2016 nonaggression pact.

We describe ancillary municipality characteristics, household survey, and crime data in Appendix B.

\section{Model of Gang Competition and Collusion}

To help guide our empirical analysis, we start with a simple theoretical framework motivated by our fieldwork and by discussions with our partner firm. In the model, gangs compete over extortion territory. The model implies that gangs can increase extortion by agreeing not to compete for territory when it is costly to both collect extortion and compete with rivals.

\subsection{Model Setup}

A firm is the sole supplier of a homogeneous good. In the empirical setting, this firm is a distributor that sells goods to retailers. ${ }^{12}$ The firm has marginal cost normalized to zero and faces linear demand $Q_{d}\left(p_{d}\right)=\alpha_{d}-\beta p_{d}$, where $p_{d}$ is the price and $Q_{d}$ is total quantity. Demand may differ across municipalities indexed by $d$, and the firm may set a different price, $p_{d}$, in different municipalities. We assume $\beta>0$ and $\alpha_{d}>0$.

There are two identical gangs that use violence to compete for territory. The larger the territory a gang controls, the larger the share of firm sales they can extort. Gang $g$ chooses violence level $h_{g d}$. Territory share is increasing in own violence, but there are decreasing returns to violence. This assumption is common in the theoretical literature on conflict and gangs (Skaperdas 1996; Castillo and Kronick 2020).

We assume that territory share for gang $g$ is given by

$$
s_{g d}=\frac{1}{2}+\left(h_{g d}\right)^{\frac{1}{2}}-\left(h_{-g d}\right)^{\frac{1}{2}}
$$

in a period in which gang $g$ uses violence $h_{g d}$ and the rival gang, $-g$, uses violence $h_{-g d}$.

\footnotetext{
${ }^{11}$ We observe admission date in the MINSAL data and discharge date in the ISSS data. Otherwise, the two data sources have the same information.

${ }^{12}$ In the context of the model, the retailers are assumed to be perfectly competitive.
} 
This is a particular case of a difference-form contest success function. ${ }^{13}$

When a gang controls share $s_{g d}$ of the territory, they can charge extortion rate $e_{g d}$ to share $s_{g d}$ of the firm's demand in that territory. The firm must pay, given the threat of violence by the gang. The firm chooses its price (or output quantity) to maximize profit after the gang commits to an extortion rate. In this way, the gang acts like an upstream firm while the distributor is the downstream firm. ${ }^{14}$

Fighting a rival gang and collecting extortion are costly. We assume that gang cost is given by $\phi h_{g d} e_{g d}$, where $\phi>\frac{\alpha_{d}}{4}$ is a cost-shifter representing police enforcement. Motivated by the discussion in Section 2.I and Appendix A, this cost function implies that it is especially costly for gangs to both fight the rival for territory and collect extortion. This assumption about diseconomies of scope is motivated by the fact that gangs may have a limited number of gang members that specialize in activities, making it costly to both engage in extortion and fight for territory. In addition, conflict with a rival gang may make all activities more dangerous, effectively increasing the cost of collecting extortion. Finally, we assume there is a fixed cost of entry, $F$, for gangs to operate in a municipality. A gang will operate in a municipality when variable profit exceeds this fixed cost.

Gang profits are determined by extortion revenue in their territory, $s_{g d} e_{g d} q_{g d}\left(e_{g d}\right)$, and cost, $\phi h_{g d} e_{g d}$. When gangs compete, they choose the level of violence, $h_{g d}$, and extortion, $e_{g d}$, to maximize profit and solve

$$
\max _{h_{g d}, e_{g d}}\left[\frac{1}{2}\left(\frac{1}{2}+\left(h_{g d}\right)^{\frac{1}{2}}-\left(h_{-g d}\right)^{\frac{1}{2}}\right) e_{g d}\left(\alpha_{d}-\beta e_{g d}\right)-\phi h_{g d} e_{g d}\right] .
$$

\subsection{Model Equilibrium and Discussion}

We begin by considering municipalities where two gangs are present. We compare the case in which the gangs compete to the case in which the two gangs collude and maximize joint profits by assigning exclusive territory. Below, we discuss the main implications of the model. Appendix C contains additional details of the model.

Proposition 1. Violence is lower when gangs collude than when gangs compete.

When gangs compete, they have an incentive to use violence to expand territory in order to extort more of the firm's sales. Figure 3 simulates the equilibrium of the model for different levels of demand. Panel A shows that the gangs use more violence when $\alpha_{d}$ is large, corresponding to the case in which there is high demand for the underlying good.

\footnotetext{
${ }^{13}$ See, for example, Hirshleifer (1989), Baik (1998) and Che and Gale (2000).

${ }^{14}$ This vertical structure is related to the canonical model of supply chains proposed by Spengler (1950).
} 
Figure 3

Simulated Extortion, Prices, and Violence as a Function of Demand Under Competition and Collusion

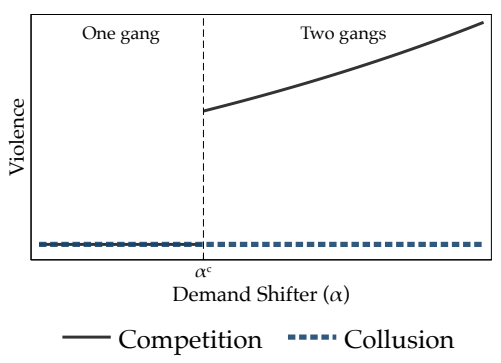

Panel A: Violence $\left(h_{g d}\right)$

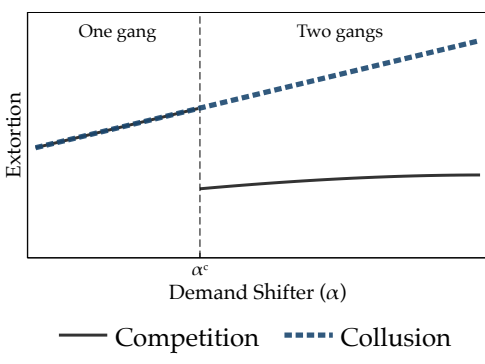

Panel B: Extortion $\left(e_{g d}\right)$

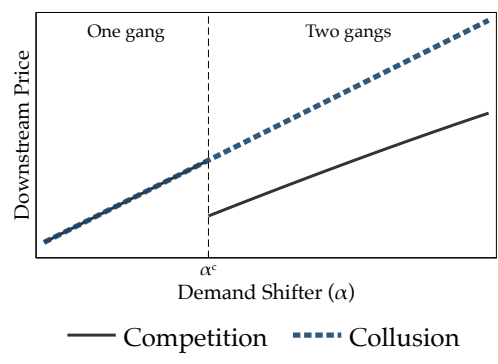

Panel C: Price $\left(p_{g d}\right)$

Notes: The figures show simulated outcomes for the model in Section 3.1, where gangs choose violence and the extortion rate. The vertical line shows the threshold, $\alpha^{c}$, for entry by a second gang. When $\alpha<\alpha^{c}$, there is a monopoly gang that is unaffected by a collusive agreement. When $\alpha \geq \alpha^{c}$, there are two gangs that compete. In this case, collusion decreases violence and increases extortion and downstream prices. The simulation assumes $\beta=15$, $\phi=1$, and $F=0.015$. The $\mathrm{x}$-axis shows $\alpha \in[2.2,3]$.

In other words, the gang's incentive to fight rivals for territory is greater when extortion is more profitable.

When gangs collude, they maximize joint profit and split the market rather than compete for territory, implying $s_{g d}=\frac{1}{2}$. In this case, using violence against the rival gang is unnecessary. This is consistent with the large, well-documented reduction in homicides after the start of both the 2012 truce and the 2016 nonaggression pact.

Proposition 2. Extortion is higher when gangs collude than when gangs compete.

Gangs choose the extortion rate knowing that higher extortion will increase consumer prices. When gangs compete, it is costly to both collect extortion and fight the rival gang for territory.

However, when gangs collude, the gang can set the same extortion rate as in the case where there is a monopoly gang in an area. In other words, they focus on extracting extortion from firms in their territory rather than expanding territory. As Figure 3 Panel B shows, this increases the extortion rate. In Appendix $C$, we show that this also increases gang profits.

The model also implies that gangs price-discriminate when demand differs across markets or products. Figure 3 Panel B shows extortion as a function of $\alpha_{d}$. When the demand curve in a market is more inelastic, there is more scope for the gang to charge high extortion. This effect is exacerbated when gangs collude.

Proposition 3. Downstream prices are higher when gangs collude. 
When gangs collude and increase extortion, this in turn increases prices for consumers relative to the case in which gangs compete. This can be seen in Figure 3 Panel C. In the model, there is double-marginalization: a gang sets the extortion rate, which increases cost for the firm, and in turn the firm adds an additional markup. In general, the degree of pass-through of extortion to downstream prices when firms have market power depends on the specific demand function and is ultimately an empirical question.

The case in which a single gang monopolizes a municipality is also shown in Figure 3. This is the case when $\alpha_{d}<\alpha_{d}^{c}$, where $\alpha_{d}^{c}$ is a cutoff such that a second gang cannot profitably enter a municipality. In these municipalities, collusion between the gangs has no effect on violence, extortion rates, or downstream prices, since the gang is already charging the monopoly extortion rate. These municipalities form our control group in our empirical analysis.

Taken together, the model offers several implications that guide our empirical analysis. The model highlights that gangs use violence to compete for extortion territory in addition to threatening violence in order to collect extortion. The model implies that a collusive agreement between the gangs allows gangs to shift resources to collecting extortion. We examine this mechanism in our empirical analysis.

\section{Descriptive Analysis}

We first examine route-level extortion and deliveries, and we explore how extortion payment amounts vary with respect to the value of each delivery. In line with accounts from the company's security team, we show two main results. First, extortion is higher for higher-value deliveries. Second, gangs use local, observable proxies for demand when setting extortion amounts. These results shed light on how gangs use price discrimination across locations. We then analyze what municipality-level characteristics are correlated with extortion payment amounts. These results provide initial correlational evidence consistent with the theoretical model in Section 3 and motivate our empirical strategy.

\subsection{Route-Level Analysis of Extortion}

Finding 1. Extortion is increasing in delivery values.

Figure 4 presents binscatter charts showing the relationship between the log extortion payment made by the firm upon a delivery and the log value of the nearest delivery (Panel A) and the log value of all goods in the truck at the time of the nearest delivery (Panel B). 
Figure 4 Panel A shows a positive relationship between the value of the goods being delivered and the extortion payment. This result implies that extortion payments are not fixed fees and instead vary according to what is being delivered. It also suggests that gangs have some information about demand for the good being delivered and set an extortion amount accordingly, consistent with the distributor's accounts and the model presented in Section 3. However, the correlation between extortion and delivery values is modest: a $1 \%$ increase in the value of delivery is associated with a $0.04 \%$ increase in extortion.

Figure 4

Relationship Between Extortion Payment Amount and Delivery Values

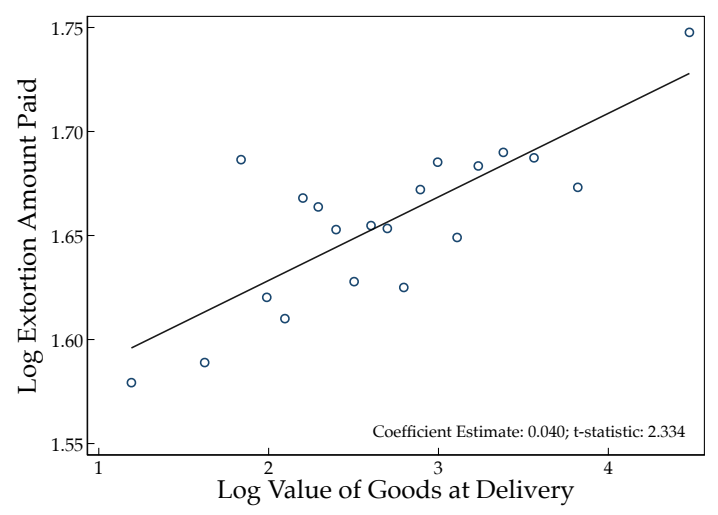

Panel A: Value of Goods at Delivery

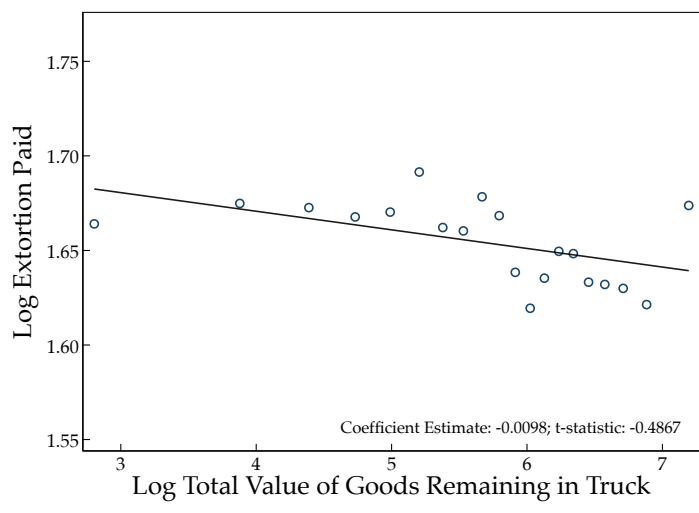

Panel B: Value of Goods in Truck

Notes: The figure presents binscatter charts between the log of the extortion amount paid by the firm upon delivery and the value of goods delivered (Panel A) and the total value of goods delivered by the truck on the date (Panel B). The unit of observation is an extortion payment-delivery pair. The bottom-right of each figure presents the estimated bivariate coefficient and $t$-statistic. Standard errors are clustered at the delivery-route level.

\section{Finding 2. Extortion payment amounts depend on local observable characteristics.}

What characteristics do gangs use to proxy for demand and price discriminate across locations? First, we ask whether gangs set local extortion payment amounts based on all deliveries made on a route on a given day (including outside gang territory) or based on local characteristics of the deliveries and retailers. To explore this, Figure 4 Panel B examines whether a relationship exists between extortion and the value of goods remaining in the truck. We find little relationship between the total value of goods remaining in the truck upon delivery and the extortion payment paid by the firm. This suggests that gangs do not generally set extortion based on the trucks' contents. This finding is consistent with our conversations with the firm, where they noted that gangs rarely look inside the firm's truck 
before setting an extortion demand. Instead, they noted that gangs focus more on proxies of the value of a delivery (e.g. the characteristics of the retailer receiving the delivery) instead of vehicle contents.

To investigate the extent to which variation in extortion can be explained by local characteristics, Table A-2 presents regression estimates for the relationship between extortion amounts and the value of deliveries when we include various fixed effects. Column 1 presents estimates with no fixed effects, while columns 2-4 sequentially include municipality, route, and retailer fixed effects, respectively. Conditioning on these time-invariant characteristics increases the adjusted $R^{2}$ from less than 0.01 in column 1 to over 0.54 in column 4. The results in Table A-2 suggest that retailer characteristics explain a considerable amount of the variation in extortion amounts, consistent with gangs using local proxies for product demand to price-discriminate.

\section{Finding 3. Extortion is unrelated to extortion payments elsewhere on a route.}

How are extortion payments related to the number of extortion payments made elsewhere along a route? If gangs set extortion payment amounts primarily using local characteristics (rather than the delivery firm's characteristics), then we would expect the amount of extortion paid to be unrelated to extortion payments elsewhere on a route. However, if gangs set extortion in a centralized manner using knowledge of the firm's delivery routes, they might extract higher extortion payments along routes facing fewer extortion payments. Similarly, if gang extortion acts as a vertical chain of "tolls," then we would expect that gangs extract more extortion along routes with fewer extortion payments. Figure A-6 presents the relationship between extortion payment amounts and the number of extortion payments made elsewhere on a route. We find little correlation which suggests that gangs do not determine extortion payment amounts using characteristics of the firm's delivery routes.

\subsection{Municipality-Level Analysis of Extortion}

Finding 4. Extortion is positively correlated with proxies for downstream demand.

We examine how municipality-level proxies for development correlate with extortion. Figure 5 presents binscatter charts for the relationship between log of the average yearly extortion paid by the firm in a municipality and various municipality-level characteristics related to firm delivery values and economic development. Figure 5 Panel A explores the relationship between extortion and delivery values. In line with the findings in Section 4.I, extortion

is higher in municipalities with higher delivery values. Figure 5 Panel B examines how the 
log of average nightlights per year is correlated with extortion. The results show that higher levels of economic development, which is likely correlated with higher demand for goods, are associated with higher extortion. This result provides additional evidence that gangs set extortion payment amounts that depend on downstream demand.

Figure 5

Municipality-Level Correlates of Extortion Payment Amounts

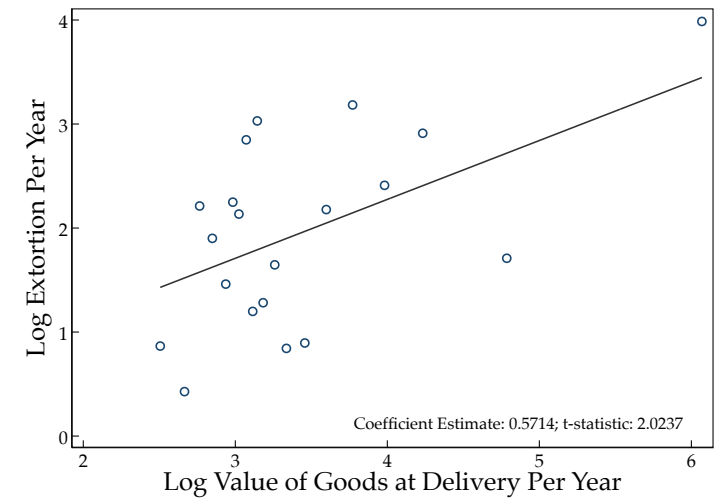

Panel A: Value of Deliveries

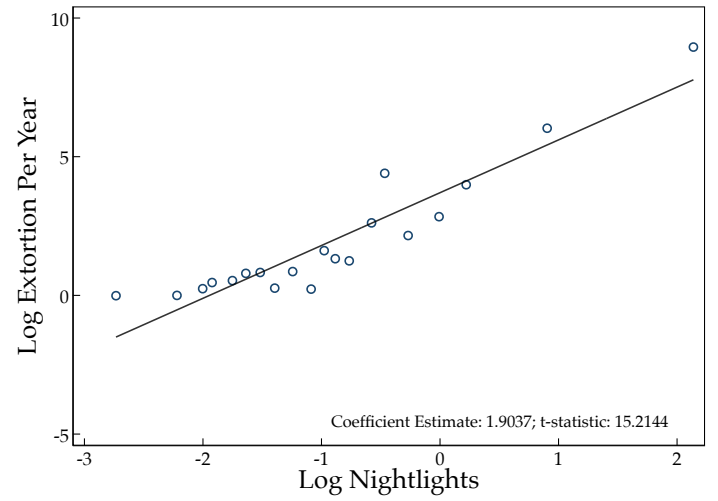

Panel B: Nightlights

Notes: The figure presents binscatter charts depicting the relationship between the log of the average yearly extortion amount paid by the firm in a municipality and (Panel A) the log of the average value of deliveries, and (Panel B) the log of average nightlights per year. The unit of observation is a municipality. The bottom-right of each figure presents the estimated bivariate coefficient and t-statistic. Standard errors are clustered at the municipality level.

Finding 5. Extortion is positively correlated with higher gang violence and competition.

Given that development is endogenous to gang presence, we next examine how extortion is related to gang competition. While we examine the causal relationship in Section 5, we first explore the cross-sectional correlation. Figure 6 Panel A presents a binscatter chart showing the relationship between the average yearly extortion paid by the company and average homicides across municipalities. We find a positive relationship between extortion and homicides. Figure 6 Panel B presents a binscatter chart showing the correlational relationship between extortion and a proxy of gang competition: a homicide Herfindahl-Hirschman Index (HHI) that uses the share of homicides in a municipality committed by MS-13 or Barrio 18 in the three years prior to the 2016 nonaggression pact (defined in more detail in Section 5.2). We find that higher gang competition is correlated with higher extortion. This noncausal result is broadly consistent with the correlation found in surveys between competition and extortion (Magaloni et al. 2020a,b). 
Figure 6

Relationship Between Extortion Amount and Gang Violence

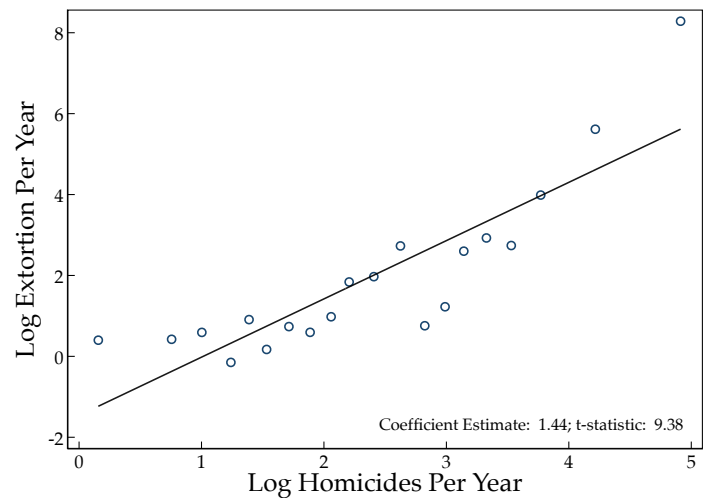

Panel A: Homicides

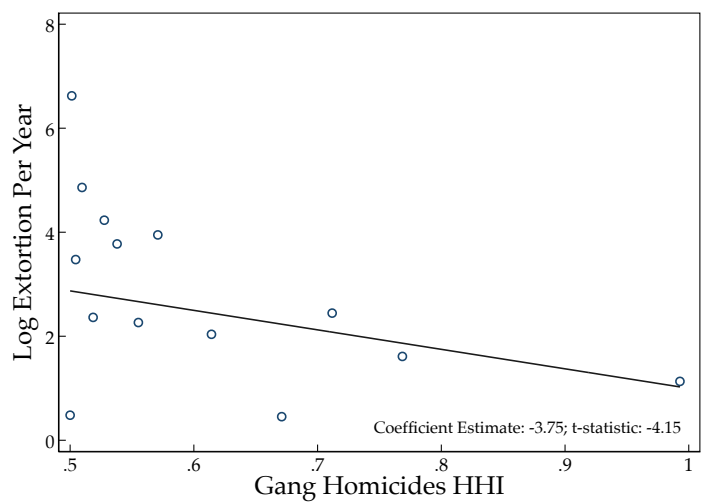

Panel B: Gang Competition

Notes: The figure presents binscatter charts depicting the relationship between the log of the average extortion amount paid by the firm upon delivery and (Panel A) the log of the number of homicides per year, and (Panel B) the homicide Herfindahl-Hirschman Index (HHI), defined using the share of homicides in municipality committed by MS-13 or Barrio 18 in the three years prior to the 2016 nonaggression pact. The unit of observation is a municipality. The bottom-right of each figure presents the estimated coefficients and t-statistics.

However, from these correlational results, it is difficult to determine whether gang competition causes higher levels of extortion, or whether some omitted variables determine both extortion amounts and gang competition (e.g., downstream demand). In particular, the model implies that in markets with high demand $(\alpha)$, gangs have a greater incentive to charge higher extortion and compete for territory using violence. Yet, the model also predicts that a reduction in gang competition will increase extortion. Therefore, despite a positive correlation between competition and extortion payment amounts across municipalities, the causal effect of collusion could imply that competition has a negative effect on extortion.

\section{Effects of the Nonaggression Pact on Extortion}

To examine the causal effect of a change in competition between gangs on extortion, we focus on the 2016 nonaggression pact between gangs. We first detail our empirical strategy and show that the pact did induce a significant decrease in gang competition. We then show how the 2016 pact affected extortion. 


\subsection{Empirical Strategy}

We exploit two sources of variation to estimate the causal effect of gang competition on extortion and prices: the timing of the 2016 pact between the two main gangs, and crosssectional variation in gang competition prior to the pact. We explore impacts at both the intensive and extensive margin.

The baseline specification is

$$
y_{d t r}=\beta\left(\text { NonAggr }_{t} \times \operatorname{Comp}_{d}\right)+\gamma_{t}+\gamma_{d}+\gamma_{r}+\theta X_{d t}+\epsilon_{d t r i}
$$

where $y_{d t r}$ is the outcome of interest (e.g., extortion amount) in municipality $d$ at month $t$ along route $r$; NonAggr $r_{t}$ is an indicator variable equal to one if month $t$ is after the pact began, and zero otherwise; Comp $p_{d}$ is an indicator variable equal to one if the municipality $d$ had gang competition prior to the pact (defined in more detail in the next section). We include municipality fixed effects, $\gamma_{d}$, and route fixed effects, $\gamma_{r}$, which control for timeinvariant factors that may be correlated with extortion amounts and gang competition. We also include month fixed effects, $\gamma_{t}$, which control for time-varying factors that may be correlated with aggregate changes in extortion across time. Additional controls, $X_{d t}$, include pre-pact municipality-level literacy, educational attainment, and employment interacted with year, and an indicator for whether a municipality in month $t$ was part of Plan Secure El Salvador (PESS), an initiative to increase police enforcement that was rolled out in select areas starting in 2015 .

In more demanding specifications, we also include route-by-municipality fixed effects $\left(\gamma_{r} \times \gamma_{m}\right)$ and route-by-post-pact $\left(\gamma_{r} \times N o n A g g r_{t}\right)$ fixed effects to exploit only within-route changes in trends in extortion across municipalities over time (before and after the pact). $\epsilon_{d t r}$ is a vector of idiosyncratic random errors. To account for correlation within a municipality across time in extortion and prices, we present standard errors clustered at the municipality level as well as Conley (1999) standard errors that allow for spatial correlation and temporal interdependence (Colella et al. 2019). ${ }^{15}$

When estimating the effect of the pact on extortion, we focus on a relatively short period around the pact, June 2015 to January 2018, for two reasons. First, the way extortion was recorded changed in June 2015. Starting that month, the distributor began validating extortion payments, making the data more reliable. Second, using a relatively short period around the pact addresses concerns about other government policies or changes in gang

\footnotetext{
${ }^{15}$ For some outcomes of interest (e.g., gang homicides), data is at the municipality-month level rather than the municipality-route-month level. For these outcomes, we do not include route fixed effects or route-bymunicipality fixed effects.
} 
structure that may have affected competition long before or after the pact (e.g., the 2012 truce). Nevertheless, we show event-study estimates and conduct robustness exercises using extortion data from before June 2015.

The coefficient of interest in equation (3), $\beta$, is interpreted as the change in the extortion amount due to the change in gang competition following the pact. The main identifying assumption is that in the absence of the pact, extortion amounts would follow common trends in areas with and without competition. We use several methods to examine the validity of the common-trends assumption, including examining trends prior to the pact and examining the robustness of results to using the synthetic difference-in-difference approach of Arkhangelsky et al. (2021). In addition, for equation (3) to identify an effect of gang competition on extortion or prices, the pact must have meaningfully decreased competition between gangs. We start by examining this issue in Section 5.2.

\subsection{Measuring Gang Competition}

To create our measure of gang competition in a municipality prior to the pact, we construct the Herfindahl-Hirschman Index (HHI) in each municipality. Information about the location of gangs over the period is limited. Therefore, we use homicides committed by gangs prior to 2016 to define our primary measure of competition, because these are an observable, meaningful outcome of gang competition. Gangs use violence to fight rival gangs for territory as well as to threaten extortion targets and other nongang members. The basic assumption is that municipalities where both gangs are committing many homicides have gang competition.

To construct the HHI, we define $s_{d, m s 13}$ and $s_{d, b 18}$ as the share of homicides in municipality $d$ committed by MS-13 or Barrio 18 in the three years prior to the pact. ${ }^{16}$ We remove municipalities with one or no homicides, given that gangs may not be present in these areas and competition is not well-defined; however, our results are robust if we treat these municipalities as having no competition. We construct the HHI for a municipality $d$ as $H H I_{d}=\sum_{g=m s 13, b 18} s_{d, g}^{2}{ }^{17}$ We then define an indicator for competition, Comp $p_{d}$, as having a low HHI. While we explore a variety of cutoffs for defining competition, our baseline specification defines Comp $\mathrm{C}_{d}$ as an indicator equal to zero if $H H I_{d}$ is in the top quartile of

\footnotetext{
${ }^{16}$ Barrio 18 split into two factions in the early 2010s: Revolucionarios in the north and Sureños in the south. The data do not separate homicides committed by these two factions prior to 2015; however, as implied by their names, Revolucionarios and Sureños tend to be geographically separated, and so there is limited competition between them (Amaya and Martínez 2015). Other gangs in El Salvador commit only a very small share of homicides.

${ }^{17}$ Appendix Figure A-2 presents municipality-level maps of homicides and homicide HHIs, while Appendix Figure A-4 presents the histogram of our homicide HHI measure.
} 
Figure 7

Gang Homicides by Competition

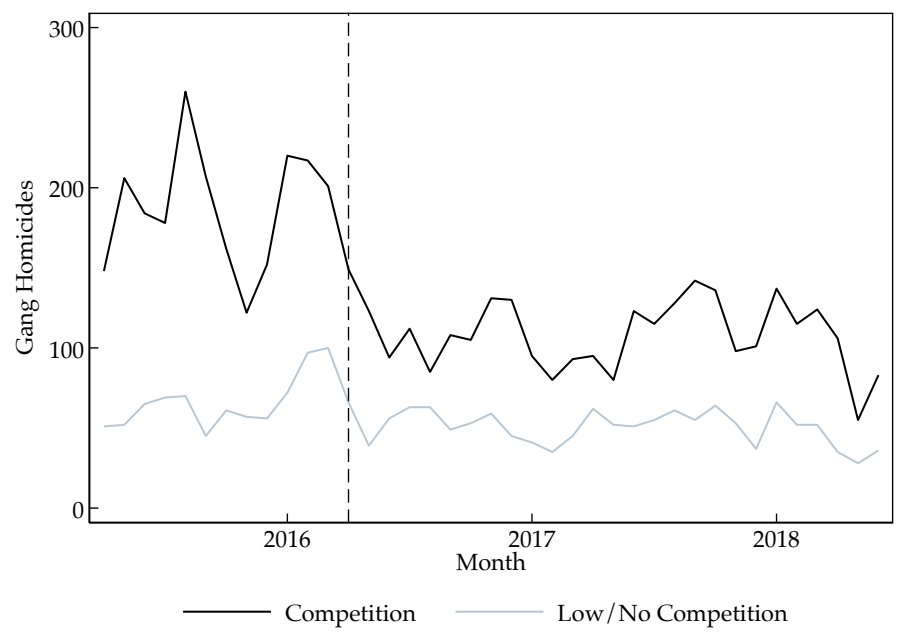

Notes: This chart shows homicides in which gangs were victims or perpetrators in municipalities with gang competition and without gang competition, as defined by the homicide Herfindahl-Hirschman Index. The vertical line shows the start of the nonaggression pact (April 2016).

municipalities and one otherwise.

We validate this measure of gang competition in two ways. First, we show that the pact between the gangs affected homicides in the municipalities we define as having competition before the pact but not the areas without prior competition. Figure 7 presents the number of homicides in which gangs were perpetrators or victims in municipalities with gang competition and without gang competition before the pact. Unlike municipalities with gang competition, municipalities without gang competition saw little change in the number of homicides after the pact. This is consistent with the idea that violence was mainly used as a threat against nongang members in these areas rather than there being violence between the two gangs (see Column 1 of Table A-3, which present the results from estimating equation (3) on the number of homicides). Figure 7 shows that while homicide rates were higher in competing areas before the pact, there was no differential pretrend in violence in these areas relative to areas without gang competition.

Second, the pact did not have a statistically significant effect on other crimes that are less likely to be associated with gang competition, such as domestic violence, petty theft, and robberies (see columns 2 to 4 of Table A-3). The results imply that the pact mainly affected gang-on-gang violence in municipalities with prior gang competition.

These results provide evidence that the pact reduced violent competition between the gangs in municipalities with prior competition according to our HHI measure. However, 
municipalities defined as not having gang competition before the pact were largely unaffected by the truce and form a valid control group. Nevertheless, we examine the robustness of results using alternative measures of gang competition, including an alternative HHI measure based on gang affiliation and municipality of residence of inmates incarcerated in the three years prior to the 2016 pact. ${ }^{18}$

\subsection{Effect on Extortion}

Figure 8 presents the estimated effect of the pact on the extortion payment amount by period, with municipality, route, and month fixed effects. We find that in the periods before the pact, there is no significant difference in the extortion amount in municipalities with gang competition and those without competition. Municipalities with competition had similar trends in the period prior to the pact as municipalities without competition, supporting the parallel-trends assumption.

Once the gangs agreed to the pact, the extortion amount increased in municipalities where gangs previously competed relative to those where gangs did not previously compete (see Figure 8). Interestingly, the increase in extortion was gradual at first, then became significant about four months following the pact, suggesting that there might have been adjustment costs for the gangs as they reallocated resources. About a year after the pact, the increase in the extortion amount exceeds $20 \%$.

Table 2 presents the average effect on the extortion amount following the pact. We present results using different measures of competition: Panel A defines gang competition using the homicide HHI while Panel B uses the inmate HHI. In a specification with month, municipality, and route fixed effects (column 1), we find that collusion between gangs increases extortion by $22.5 \%$. This estimate is statistically significant, including when accounting for spatial correlation. We include municipality-by-route fixed effects in column 2 to control for differences across routes; the results are similar, implying a $30 \%$ increase in extortion amounts.

Table 2 column 3 includes fixed effects for routes interacted with an indicator for whether a month is after the pact to account for potential changes in routes after the pact. This specification compares the trend in extortion amounts-before and after the pact-for the portions of a route inside municipalities with gang competition to the trend along the same route for the portions of the route in municipalities with little to no gang competition. The results presented in column 3 imply that the pact increased extortion amounts by approximately $23 \%$, very similar to our baseline estimates. We also find very similar estimates using our

\footnotetext{
${ }^{18}$ Appendix Figure A-5 shows the strong correlation between the two HHI measures.
} 
Figure 8

Impact of the Nonaggression Pact on Extortion

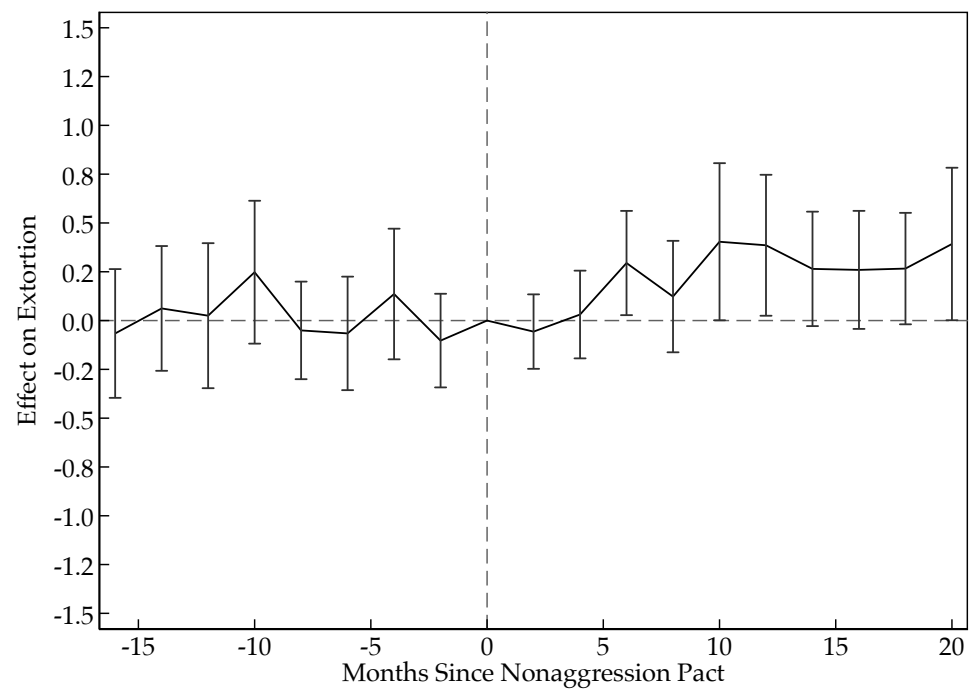

Notes: The figure shows bimonthly point estimates using the difference-in-difference specification with log extortion amounts as the outcome. The specification includes month fixed effects, municipality fixed effects, and route fixed effects, as in the baseline specification (3). We omit the period before the start of the nonaggression pact. The sample period is October 2014 to January 2018. The vertical line shows the start of the nonaggression pact (April 2016). Bimonthly periods are chosen because extortion payments sometimes cover periods of four to six weeks. Error bars indicate $95 \%$ confidence intervals using standard errors clustered at the municipality level.

alternative measure of competition using the inmate HHI: the results in Panel B suggest that extortion increased between $24 \%$ to $28 \%$ in municipalities with prior competition following the pact.

A potential confounding factor is the implementation of Plan Secure El Salvador (PESS), the initiative to increase police enforcement that was rolled out in select areas starting in 2016 (see Appendix Section A.2). In columns 4-6 of Table 2, we directly control for the implementation of PESS in a municipality. Despite the program's limited reach, interestingly, we find suggestive evidence that increased enforcement from PESS may have led to a modest decrease in extortion amounts. This result is consistent with the theoretical prediction of a change in gang cost. Nonetheless, we find that the estimated effect of the pact on extortion is robust to accounting for the implementation of PESS.

We also examine whether the pact affected the number of extortion payments; we find little evidence of an extensive margin effect. We present the effects of the pact on the probability of paying extortion in Panel A of Table A-4. The point estimates imply that the pact increased the probability of at least one extortion in a municipality-route by $0.3 \%$; however, 
Table 2

Effect of the Nonaggression Pact on Extortion in Municipalities with Gang Competition

\begin{tabular}{|c|c|c|c|c|c|c|}
\hline & \multicolumn{6}{|c|}{ Outcome: $\log ($ Extortion +1$)$} \\
\hline & $(1)$ & $(2)$ & (3) & (4) & (5) & $(6)$ \\
\hline & \multicolumn{6}{|c|}{ Panel A: Comp $p_{d}$ Using Homicide Composition } \\
\hline NonAggr $_{t} \times$ Comp $_{d}$ & $\begin{array}{l}0.225^{* *} \\
(0.097) \\
{[0.079]}\end{array}$ & $\begin{array}{l}0.301^{* * *} \\
(0.095) \\
{[0.089]}\end{array}$ & $\begin{array}{l}0.234^{* * *} \\
(0.085) \\
{[0.094]}\end{array}$ & $\begin{array}{c}0.224^{* *} \\
(0.097) \\
{[0.079]}\end{array}$ & $\begin{array}{l}0.304^{* * *} \\
(0.096) \\
{[0.089]}\end{array}$ & $\begin{array}{l}0.235^{* * *} \\
(0.085) \\
{[0.096]}\end{array}$ \\
\hline $\mathrm{PESS}_{\mathrm{dt}}$ & & & & $\begin{array}{c}-0.044 \\
(0.107) \\
{[0.079]}\end{array}$ & $\begin{array}{c}-0.136 \\
(0.113) \\
{[0.084]}\end{array}$ & $\begin{array}{c}-0.106 \\
(0.115) \\
{[0.084]}\end{array}$ \\
\hline Month-Year FEs & Yes & Yes & Yes & Yes & Yes & Yes \\
\hline Municipality FEs & Yes & No & No & Yes & No & No \\
\hline Route FEs & Yes & No & No & Yes & No & No \\
\hline Municipality-Route FEs & No & Yes & Yes & No & Yes & Yes \\
\hline Route-NonAggr $r_{t}$ FEs & No & No & Yes & No & No & Yes \\
\hline Outcome Mean & 1.95 & 1.96 & 1.96 & 1.95 & 1.96 & 1.96 \\
\hline Adjusted R2 & 0.490 & 0.642 & 0.646 & 0.490 & 0.643 & 0.646 \\
\hline \multirow[t]{2}{*}{ Observations } & 2,314 & 2,166 & 2,166 & 2,314 & 2,166 & 2,166 \\
\hline & \multicolumn{6}{|c|}{ Panel B: Comp $p_{d}$ Using Inmate Composition } \\
\hline $\operatorname{NonAggr}_{t} \times$ Comp $_{d}$ & $\begin{array}{c}0.237^{* *} \\
(0.093) \\
{[0.087]}\end{array}$ & $\begin{array}{l}0.275^{* * *} \\
(0.092) \\
{[0.092]}\end{array}$ & $\begin{array}{l}0.286^{* * *} \\
(0.088) \\
{[0.109]}\end{array}$ & $\begin{array}{c}0.235^{* *} \\
(0.094) \\
{[0.087]}\end{array}$ & $\begin{array}{l}0.279^{* * *} \\
(0.094) \\
{[0.093]}\end{array}$ & $\begin{array}{l}0.291^{* * *} \\
(0.088) \\
{[0.111]}\end{array}$ \\
\hline PESS $_{\mathrm{dt}}$ & & & & $\begin{array}{c}-0.028 \\
(0.112) \\
{[0.083]}\end{array}$ & $\begin{array}{c}-0.137 \\
(0.117) \\
{[0.086]}\end{array}$ & $\begin{array}{c}-0.118 \\
(0.116) \\
{[0.085]}\end{array}$ \\
\hline Month-Year FEs & Yes & Yes & Yes & Yes & Yes & Yes \\
\hline Municipality FEs & Yes & No & No & Yes & No & No \\
\hline Route FEs & Yes & No & No & Yes & No & No \\
\hline Municipality-Route FEs & No & Yes & Yes & No & Yes & Yes \\
\hline Route-NonAggr $r_{t}$ FEs & No & No & Yes & No & No & Yes \\
\hline Outcome Mean & 1.96 & 1.97 & 1.97 & 1.96 & 1.97 & 1.97 \\
\hline Adjusted R2 & 0.493 & 0.645 & 0.650 & 0.493 & 0.645 & 0.650 \\
\hline Observations & 2,281 & 2,137 & 2,137 & 2,281 & 2,137 & 2,137 \\
\hline
\end{tabular}

Notes: The unit of observation is a route-municipality-month. The outcome variable is the log of the amount of extortion paid in a route-municipality-month in dollars plus one. The sample period is June 2015 to January 2018. The sample includes all municipality-routes visited by the firm during the sample period. In Panel A, Comp $p_{d}$ is defined using the gang affiliation and location of homicides in El Salvador in the three years prior to the nonaggression pact. In Panel B, Comp $p_{d}$ is defined using the gang affiliation and location of residence for inmates in El Salvador arrested in the three years prior to the nonaggression pact. For both, we construct an $\mathrm{HHI}_{d}$ and define Comp $\mathrm{C}_{d}$ as an indicator variable equal to zero if $H H I_{d}$ is in the top quartile of the HHI for municipalities and one otherwise. PESS $d t$ is an indicator variable equal to one if the municipality was part of PESS at month $t$ and zero otherwise. Regressions drop "singleton" groups when including additional fixed effects (Correia 2015). Covariates include census municipality characteristics-literacy, educational attainment, employment-interacted with year. Standard errors clustered at the municipality level are in parentheses, and Conley (1999) standard errors calculated using a 10o-km cutoff window with a 20-month temporal auto-correlation window are presented in brackets (Colella et al. 2019). * $p<0.10,{ }^{* *} p<0.05,{ }^{* * *} p<0.01$. 
these results are not statistically significant. We also examine the effects of the pact on the number of extortion incidents; we find no evidence that the average number of extortion incidents changed following the pact (see Panel B of Table A-4). These results suggest that while gangs increased the average extortion amount after the pact, they did not begin to collect extortion significantly more or less frequently.

\subsection{Understanding the Increase in Extortion}

Overall, the results in Section 5.3 show that extortion payments substantially increase when gangs collude. The model and qualitative evidence highlight that gangs may shift resources toward extortion when gangs collude, given that it is costly to both collect extortion and fight rival gangs. In this section, we examine this mechanism empirically and explore alternative mechanisms.

Shifting Resources to Extortion. Gangs may have devoted more resources toward collecting extortion following the pact. In particular, gangs may have been able to increase extortion amounts by shifting resources toward monitoring and credibly threatening extortion targets. ${ }^{19}$ We examine whether reports of violent threats by the gangs increased following the pact. In Table A-5, we find a significant increase in reports of gang-related arrests for threats and no increase in non-gang-related threats. This suggests that the gangs devoted more resources to threaten violence following the pact, allowing them to demand a higher extortion amount.

Second, we examine whether the degree of price discrimination by gangs changed following the pact. If gangs are dedicating more resources to their extortion business, gangs might have better information on retailers and the associated demand for delivered goods, and might be able to better price-discriminate. We present the results in Table A-6; we find suggestive evidence that after the pact, gangs increased extortion more for deliveries at retailers with higher delivery values.

Finally, we explore how firm delivery times change following the pact. If gangs devote more resources to extracting higher extortion payments, it is possible that delivery times will increase, given that collecting extortion may be more difficult when rates are higher. We present the results in Table A-7; we find suggestive evidence that the time between extortion payments and deliveries increases following the pact, consistent with the idea that gangs are willing to spend more time demanding higher payments.

Changes in Downstream Demand. The model and the results in Section 4.2 highlight that higher downstream demand is associated with higher extortion. Therefore, extortion may

\footnotetext{
${ }^{19}$ In Appendix A, we discuss how gangs use threats to ensure compliance and maximize extortion demands.
} 
have increased if the reduction in violence due to the nonaggression pact considerably increased downstream demand. In Appendix Table A-8, we directly examine the effect of the pact on per capita household incomes, per capita household expenditures, and nightlight intensity; we find no statistically significant effect in our sample period. This suggests that downstream demand did not increase substantially in the short run following the pact.

Firm Adjustments. We also explore whether the results might be explained by the firm adjusting delivery locations or routes following the pact. We find little evidence that the firm adjusted their routes or the retailers served following the pact (see Figures A-7 and A-8). Furthermore, in Section 6, we explore in detail how the firm responded to the increase in extortion, and we find that the distributor mostly adjusted via prices rather than along the extensive margin following the pact. This is because the firm often has enduring delivery relationships with retailers and is the sole distributor for many goods. These firm-level findings suggest that changes in the composition of routes used or retailers served is unlikely to explain the findings.

Price Competition. It could be that, when there is gang competition, firms choose to pay the gang that provides "protection" for the lowest cost. However, our conversations with the distributor highlight that the firms paying extortion cannot choose which gang to pay for protection; instead, firms must pay whichever gang is in control of the territory where they are making a delivery. For these reasons, we argue that the increase in extortion was primarily because gang collusion allowed gangs to focus resources on extortion rather than fighting for territory.

\subsection{Heterogeneous Effects on Extortion}

One implication of the theoretical model is that collusion between gangs is predicted to have a larger effect on extortion in markets with higher demand for the goods being extorted. To examine this, we estimate separate regressions by geographic characteristics that are likely to reflect demand conditions.

Figure 9 shows the estimated effect on extortion by geographic characteristics. First, we examine the results by municipality development, as measured by nightlights. The pact is estimated to increase extortion by $35 \%$ in municipalities with above-median development, but the effect is not statistically significant in municipalities with below-median development. Similarly, there is a larger effect on extortion in municipalities with high population density. Finally, we examine total sales in the surrounding canton. The pact has a larger effect in areas with above-median total sales, though the difference is not statistically significant.

Taken together, these results suggest that the pact allowed gangs to increase extortion 
Figure 9

Effect of the Nonaggression Pact on Extortion

Heterogeneous Effect by Geographic Characteristics

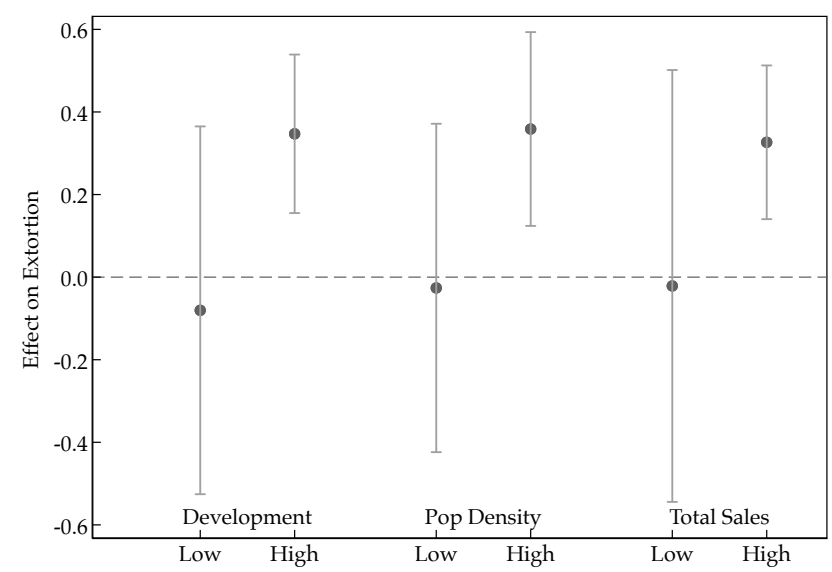

Notes: This figure shows point estimates and 95\% confidence intervals from the difference-indifference model. Low (high) characteristics are defined as being below (above) the median value in the preperiod. Standard errors are clustered at the municipality level. All specifications include municipality fixed effects, route fixed effects, month fixed effects, and controls for PESS and census municipality characteristics interacted with year.

most in regions with higher (or more inelastic) demand, consistent with the theoretical predictions in Figure 3 Panel B.

\subsection{Robustness}

One of the primary concerns is that our results are driven by the definition of gang competition prior to the pact. We address this concern by estimating specifications using alternative measures of competition.

The cutoff we use to define competition in our baseline estimates reflects the areas most likely to be affected by the pact. However, we examine how the estimated effect on extortion differs for a wide range of cutoffs for defining competition. The estimates, presented in Appendix Table A-9, are quite similar to the baseline, ranging from $18 \%$ (50th percentile) to $30 \%$ (8oth percentile).

It is possible that areas defined as not having competition are still somewhat affected by the pact, leading to an underestimate of the effect. Rather than use a binary measure of competition, we also estimate an alternative model using $H H I_{d}$ as a continuous treatment measure. The results, which are qualitatively similar to the baseline specification, are presented in Appendix Table A-10. The point estimates, which are all significant, imply that if a municipality were to go from a duopoly in which the two gangs split the market equally 
$\left(H H I_{d}=1 / 2\right)$ to fully collusive $\left(H H I_{d}=1\right)$, extortion would increase by approximately $50 \%$.

Relatedly, there is concern that areas without homicides should be included in the control group. Interestingly, the results are quite similar to the baseline results when we include municipalities without homicides as part of the control group (see Table A-II). In addition, we show that the results are similar when we expand the sample period to include the full period for which we have extortion data (see Table A-12).

One strength of using the HHI measure to define competition-where we use the composition of homicides or inmates rather than levels-is that it is more robust to concerns about mean reversion following the pact. Nevertheless, in Table A-14 we show that the results are robust to using an HHI defined various years before the pact. This is consistent with the fact that the HHI measure is quite stable over time.

We also show that the results are robust to recent synthetic difference-in-differences estimators that weaken the reliance on parallel-trend assumptions (Arkhangelsky et al. 2021). This method also addresses concerns about testing for parallel trends (Roth 2022). We present the results in Table A-13. These results are also similar to the baseline specification.

Finally, to address the concern that gang competition also varies within a municipality, we replicate our analysis using smaller geographic units. The 262 municipalities are subdivided into 2,286 cantons. Using the address of each homicide, we determine the canton for the event and construct our measure of gang competition at the canton level rather than the municipality level. We then replicate our previous analysis at the canton level and present the results in Table A-15. Despite concerns about measurement error due to geocoding, estimates are largely similar to the baseline specification and imply an increase in extortion of between $17 \%$ and $22 \%$.

\section{Effect on Distributor Behavior}

Understanding how extortion affects downstream firms and consumers helps shed light on who bears the cost of extortion. In this section, we examine whether the distributor increased prices or changed deliveries in response to the increase in extortion. In particular, we examine whether the nonaggression pact and resulting increase in extortion affected the distributor's margin. This provides insight into the incidence of extortion. We also examine whether the distributor changed the number of deliveries in response to the pact. In Section 7 , using administrative data from pharmacies, we directly examine the effect on 
consumer prices for a subset of the goods.

\subsection{Effects of Extortion on Distributor Margins}

To examine the causal effect of gang competition on the distributor's behavior, we modify our baseline difference-in-differences specification to take advantage of the richness of the distributor's sales data. We estimate the following specification:

$$
y_{d t j i}=\beta N_{o n A g g r} \times \operatorname{Comp}_{d j}+\gamma_{t}+\gamma_{d}+\gamma_{j}+\theta X_{d t}+\epsilon_{d t j i}
$$

where $y_{d t j i}$ is the outcome of interest (e.g., gross margin) for a delivery $i$ for retailer $j$ in municipality $d$ at month $t$. We include retailer fixed effects, $\gamma_{j}$, to finely control for timeinvariant unobservables. In particular, retailer fixed effects address concerns that the pact affected the composition of retailers. As an additional robustness check, we include route fixed effects. The remaining variables are defined as in equation (3).

To examine whether extortion causes the distributor to increase prices for retailers, we focus on the gross margin as the primary outcome. The gross margin is defined as the difference between revenue amount (paid by the retailer to the distributor) and procurement cost (paid by the distributor to the manufacturer) for a given product. For instance, the distributor may sell $\$ 200$ of acetaminophen $500 \mathrm{mg}$ tablets to a retailer that it purchased from a manufacturer from $\$ 150$. In this case, the margin is $\$ 50$. While we do not observe quantity or price per unit for each good (e.g., price per tablet), the margin captures a key measure of cost to the retailer. From the perspective of retailers, the distributor margin can be thought of as the delivery fee for a given product.

Table 3 presents the estimated effect of the 2016 pact on the distribution firm's gross margin. In all cases, we link extortion and retailers for deliveries occurring on the same date and same route. In columns 1 and 2, we focus on retailers closest to an extortion payment; they are the most likely to be affected by an increase in extortion. Extortion payments may also affect prices for multiple nearby retailers; in columns $3-6$, we examine retailers $1 \mathrm{~km}$ and $5 \mathrm{~km}$ away from an extortion payment.

Column 1 of Table 3 shows that after the pact, the distributor's margin increased by $11.6 \%$ for deliveries that occur closest to extortion payments. Using the estimated effect of the pact on the level of extortion in Table 2, this implies that a $\$ 1$ increase in extortion leads to a nearly $\$ 1$ increase in the amount charged to retailers. In column 2, which includes route fixed effects, we find a slightly larger increase in the margin due to the pact.

Retailers further from the extortion saw a smaller increase in gross margins. While the 
Table 3

Effect of the Nonaggression Pact on Distributor Margin

\begin{tabular}{|c|c|c|c|c|c|c|}
\hline & \multicolumn{2}{|c|}{ Nearest Sale } & \multicolumn{2}{|c|}{ Sales Within $1 \mathrm{Km}$} & \multicolumn{2}{|c|}{ Sales Within $5 \mathrm{Km}$} \\
\hline & (1) & (2) & (3) & (4) & (5) & (6) \\
\hline $\operatorname{NonAggr}_{t} \times$ Comp $_{d}$ & $\begin{array}{l}0.121^{* *} \\
(0.055) \\
{[0.032]}\end{array}$ & $\begin{array}{l}0.154^{* * *} \\
(0.048) \\
{[0.033]}\end{array}$ & $\begin{array}{l}0.121^{* *} \\
(0.052) \\
{[0.045]}\end{array}$ & $\begin{array}{l}0.086^{* *} \\
(0.041) \\
{[0.061]}\end{array}$ & $\begin{array}{c}0.059 \\
(0.049) \\
{[0.020]}\end{array}$ & $\begin{array}{l}0.034 \\
(0.022) \\
{[0.022]}\end{array}$ \\
\hline $\begin{array}{l}\text { Municipality FEs } \\
\text { Route FEs } \\
\text { Month-Year FEs } \\
\text { Retailer FEs }\end{array}$ & $\begin{array}{l}\text { Yes } \\
\text { No } \\
\text { Yes } \\
\text { Yes }\end{array}$ & $\begin{array}{l}\text { Yes } \\
\text { Yes } \\
\text { Yes } \\
\text { Yes }\end{array}$ & $\begin{array}{l}\text { Yes } \\
\text { No } \\
\text { Yes } \\
\text { Yes }\end{array}$ & $\begin{array}{l}\text { Yes } \\
\text { Yes } \\
\text { Yes } \\
\text { Yes }\end{array}$ & $\begin{array}{l}\text { Yes } \\
\text { No } \\
\text { Yes } \\
\text { Yes }\end{array}$ & $\begin{array}{l}\text { Yes } \\
\text { Yes } \\
\text { Yes } \\
\text { Yes }\end{array}$ \\
\hline $\begin{array}{l}\text { Outcome Mean } \\
\text { Adjusted R2 } \\
\text { Observations }\end{array}$ & $\begin{array}{c}1.03 \\
0.443 \\
34,571\end{array}$ & $\begin{array}{c}1.03 \\
0.445 \\
34,570\end{array}$ & $\begin{array}{c}0.99 \\
0.444 \\
40,447\end{array}$ & $\begin{array}{c}0.99 \\
0.447 \\
40,444\end{array}$ & $\begin{array}{c}0.99 \\
0.439 \\
143,194\end{array}$ & $\begin{array}{c}0.99 \\
0.442 \\
143,194\end{array}$ \\
\hline
\end{tabular}

Notes: The unit of observation is a delivery. Distributor margin is defined as the difference between wholesale price and manufacturer price. Columns (1) and (2) show the effect on sales closest to where a extortion payment was made. Columns (3) and (4) show the effect on sales within $1 \mathrm{~km}$ of an extortion payment. Columns (5) and (6) show the effect on sales within 5 $\mathrm{km}$ of an extortion payment. Specifications include controls for PESS and census municipality characteristics interacted with year. The sample period is June 2015 to January 2018. Regressions drop "singleton" groups when including additional fixed effects (Correia 2015). Standard errors clustered at the municipality level are in parentheses, and Conley (1999) standard errors calculated using a $100 \mathrm{~km}$ cutoff window with a 20-month temporal auto-correlation window are presented in brackets (Colella et al. 2019). ${ }^{*} p<0.10,{ }^{* *} p<0.05,{ }^{* * *} p<0.01$.

estimates for sales within $1 \mathrm{~km}$ are similar, we find only a $5.0 \%$ increase in the gross margin for deliveries within $5 \mathrm{~km}$ of extortion payments. With route fixed effects, the point estimate implies a $1.8 \%$ increase in the gross margin. These estimates are not statistically significant.

Overall, these estimates are broadly consistent with the model presented in Section 3. When the distributor pays higher extortion due to gang collusion, they raise prices (and gross margin). The increase in prices most acutely affected retailers closest to the extortion payments.

\subsection{Heterogeneous Effects of Extortion on Distributor Margins}

When extortion increases due to gang collusion, which products are most effected by the increase in prices? The theoretical model implies that there may be a larger effect for products with relatively inelastic demand. To examine this, we estimate separate regressions by product groups that are likely to differ in their demand elasticity. To define product groups, we focus on the 500 most common products delivered by the distribution firm, dividing them into five categories: staple food products, nonstaple foods, cleaning supplies, toiletries, and nonpharmaceutical health products. We exclude pharmaceutical health products because 
Figure 10

Effect of the Nonaggression Pact on Extortion and Distribution Margins

Heterogeneous Effects by Product
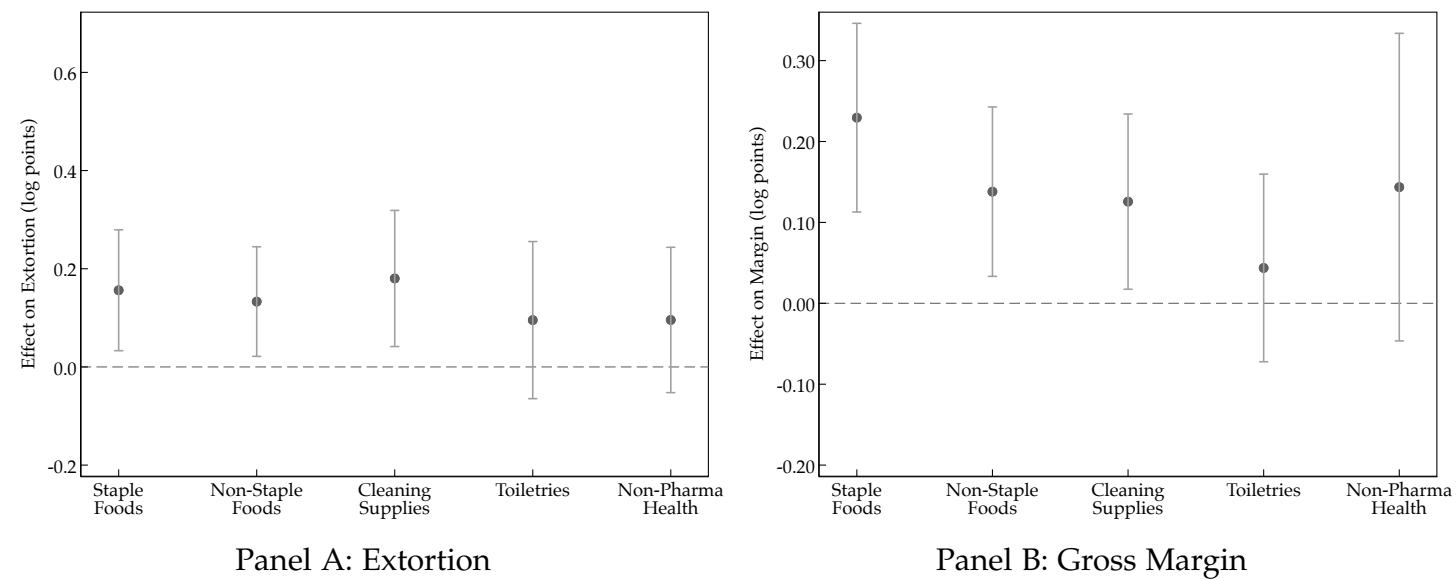

Notes: This figure shows point estimates and 95\% confidence intervals for the difference-in-differences model. Distributor margin is defined as the difference between wholesale price and manufacturer price. The sample period is June 2015 through January 2018. All specifications include municipality fixed effects, route fixed effects, month fixed effects, retailer fixed effects, and controls for PESS and census municipality characteristics interacted with year. Standard errors are clustered at the municipality level.

we examine these directly in Section 7 .

Figure 10 Panel A shows the estimated effects of the pact on extortion payments made near deliveries with different types of products. These results imply a similar increase in extortion across the product groups, and they are consistent with the qualitative evidence that gangs do not look inside the trucks and set the extortion amount based on the products being delivered. Rather, the gangs use observable characteristics of overall demand to set the amount (such as the characteristics examined in Figure 9).

However, the results in Figure 10 Panel B show evidence of heterogeneous adjustment effects by the distributor by product groups. Distributor margins increase the most for goods that likely have inelastic demand, such as staple foods. The distributor does not significantly adjust prices for toiletries and nonpharmaceutical health products, which may have more elastic demand.

Taken together, the results presented in Figure 10 suggest that the pact did not lead to heterogeneous increases in extortion by product type, but did induce heterogeneous downstream adjustments by the distributor. The results suggest a larger increase in distributor margins for inelastic products, consistent with the theoretical predictions in Figure 3 Panel C. Also, the results suggest that-because they affect staple food products the most-increases 
in extortion due to gang collusion may disproportionately impact poorer households, potentially exacerbating inequality and reducing economic development.

\subsection{Effects of Extortion on the Distributor's Extensive Margin}

In addition to adjusting prices, the distributor may respond to extortion by changing the quantity or type of deliveries. In Figure $A-7$, we examine the effect of the pact by period on total cost, total deliveries, unique products, and unique retailers in a municipality-routemonth, as in equation (3). For each of these outcomes, we find no evidence of pretrends and no significant effect of the pact. This is consistent with the fact that the distributor is contractually obligated to make deliveries and is often the exclusive distributor for certain products. Given the long-standing contracts, these outcomes are unlikely to adjust within our sample period. In addition, we explore whether the distributor changed the number of routes served per municipality after the pact; we find no change (see Figure A-8). Therefore, when extortion increases in a municipality, the distributor increases prices rather than adjusting deliveries.

\section{Effect on Retailers and Consumers}

In the previous section, we show that the increase in extortion causes the distributor to raise prices, affecting retailers' cost. In this section, we examine whether this cost is passed through to consumers. To analyze this issue, we focus on pharmacies, a subset of the retailers with detailed information on consumer prices. The distributor is a major supplier of drugs from both local manufacturers and international pharmaceutical companies. Drug prices in El Salvador have historically been substantially higher than in comparable countries, making drug prices the focus of much political debate. It is important to understand whether extortion is a factor driving high drug prices, especially given the potential implications for health.

\subsection{Effect on Pharmacy Prices, Exit, and Entry}

We employ an identification strategy similar to our baseline specification to examine the effect of the 2016 nonaggression pact on pharmacy prices. Columns 1 and 2 of Table 4 present the effect for all drugs at all pharmacies in the sales sample. In column 1 , we include drug fixed effects to address concerns that changes in the composition of drugs could affect average prices. This specification implies that gang collusion resulted in a $7.6 \%$ increase in retail prices for pharmaceutical drugs. To address the concern that results may be driven by 
changes in the set of pharmacies over time, we also show, in column 2, that results are robust to the inclusion of pharmacy fixed effects. This is consistent with the fact that we find no evidence that the pact affected the number of pharmacies during our period of analysis (see Table A-17). Furthermore, Figure A-9 Panel A presents the estimated effect by period and shows no evidence of differential trends in the preperiod.

Many of the pharmacies in the sample are supplied by other distributors that are also likely to pay extortion. We examine the differential effect for the distributor that is the focus of this study by interacting the treatment indicator with an indicator for the distributor that provided the extortion data. ${ }^{20}$ The coefficients in the second row of Table 4 are very small and insignificant, implying no differential effect for the drugs supplied by this distributor. This result is consistent with all distributors being similarly affected by the increase in extortion. In this way, the results suggest that other distributors in El Salvador are similarly affected by extortion.

We also examine the subset of drugs that are important for managing chronic diseases, including diabetes, hypertension, coronary heart disease, and asthma. The cost of diabetes drugs are of particular concern, given that $9 \%$ of the Salvadoran population has diabetes, almost double the world average (see WHO Diabetes Country Profile, 2020). Many drugs for treating chronic conditions are unaffordable in El Salvador, given that drug prices there are high relative to incomes. For this sample of drugs, we also find a positive and significant effect on prices due to the pact (see Table 4 ).

These results indicate that the pact led to an increase in pharmaceutical prices for consumers. This could be due to pass-through of upstream extortion to final consumers or an increase in direct extortion of the pharmacies. According to the Ministry of Health, which oversees pharmacies, direct extortion of pharmacies is much less common than extortion of suppliers, suggesting that extortion of distributors is playing an important role. Overall, the results show that the pact further exacerbated high pharmaceutical prices in El Salvador.

\subsection{Effect on Health}

To examine whether the increase in prices due to the pact affected health outcomes, we examine visits to public hospitals (see Table 5). Given that the outcome of interest is number of visits, we employ Poisson regressions. We first examine visits for all diagnoses and find a small, statistically insignificant effect. This is not surprising, given that many hospital visits

\footnotetext{
${ }^{20}$ We identify this subset using the name and location of pharmacies. These pharmacies may have drugs supplied by multiple distributors; however, we are not able to identify the specific drugs supplied by the distributor, given that the distributor's sales data do not contain a comparable drug identifier.
} 
Table 4

Effect of the Nonaggression Pact on Consumer Prices at Pharmacies

\begin{tabular}{lccccc}
\hline & \multicolumn{2}{c}{ All Pharmacies $/$ Drugs } & & \multicolumn{2}{c}{$\begin{array}{c}\text { Drugs for Managing } \\
\text { Chronic Diseases }\end{array}$} \\
\cline { 2 - 3 } \cline { 5 - 6 } & $(1)$ & $(2)$ & & $(3)$ & $(4)$ \\
\hline NonAggr $_{\mathrm{t}} \times$ Comp $_{\mathrm{d}}$ & $0.076^{* *}$ & $0.058^{* *}$ & & $0.052^{* *}$ & $0.044^{* *}$ \\
& $(0.035)$ & $(0.028)$ & & $(0.025)$ & $(0.022)$ \\
& {$[0.008]$} & {$[0.013]$} & & {$[0.013]$} & {$[0.018]$} \\
NonAggr $_{\mathrm{t}} \times$ Comp $_{\mathrm{d}} \times$ Distr & -0.015 & 0.003 & & -0.002 & 0.000 \\
& $(0.026)$ & $(0.025)$ & & $(0.024)$ & $(0.023)$ \\
& {$[0.007]$} & {$[0.009]$} & & {$[0.017]$} & {$[0.018]$} \\
Municipality FEs & & & & Yes & Yes \\
Month-Year FEs & Yes & Yes & & Yes & Yes \\
Retailer FEs & No & Yes & & No & Yes \\
Drug FEs & Yes & Yes & & Yes & Yes \\
\hline Outcome Mean & -1.11 & -1.11 & & -0.82 & -0.82 \\
Adjusted R2 & 0.869 & 0.880 & & 0.862 & 0.870 \\
Observations & $1,755,366$ & $1,755,366$ & & 190,269 & 190,269 \\
\hline
\end{tabular}

Notes: The unit of observation is a drug-pharmacy-month, and the outcome is log(Price). The second row shows the coefficient on the treatment interacted with an indicator for whether the distributor of the drug is the firm that is the focus of our prior analysis. The sample period with available data on drug prices is December 2014 through December 2017. For the period prior to January 2016, data are available for December 2014, March 2015, and August 2015. The outcome is the price per unit (pill, milliliter, or gram, depending on the product). Covariates include PESS and census municipality characteristics interacted with year. Standard errors clustered at the municipality level are in parentheses, and Conley (1999) standard errors calculated using a $100 \mathrm{~km}$ cutoff window with a 20-month temporal auto-correlation window are presented in brackets (Colella et al. 2019). ${ }^{*} p<0.10,{ }^{* *} p<0.05$, $* * * p<0.01$.

are unlikely to be affected by drug prices. In addition, the decrease in violence due the pact may have decreased visits, counteracting the effect due to higher drug prices.

Focusing on visits for chronic conditions treated by the drugs analyzed in Table 4, we find that hospital visits increase by about $8 \%$. Columns 5 and 6 show this result is significant and robust to including controls for demographic characteristics. In Appendix Table A-16, we estimate the effect on visits for individual diagnoses that may be affected by an increase in drug prices. The results are particularly large and significant for diabetes. This is consistent with the fact that, if untreated, diabetes can cause kidney failure, heart attacks, blindness, and stroke.

The significant effect on hospital visits for diagnoses plausibly affected by high drug prices and not for other diagnoses, such as injuries, helps confirm that the increase in visits is due to the effect of the pact on drug prices. Finally, Figure A-9 Panel B examines the effect on visits for chronic conditions by period. The results imply that the effects are not driven by trends prior to the pact. 
Table 5

Effect of the Nonaggression Pact on Hospital Visits

\begin{tabular}{|c|c|c|c|c|c|c|}
\hline & \multicolumn{2}{|c|}{$\begin{array}{c}\text { All } \\
\text { Diagnoses }\end{array}$} & \multicolumn{2}{|c|}{ Injuries } & \multicolumn{2}{|c|}{$\begin{array}{l}\text { Chronic Diagnoses } \\
\text { Affected by } \\
\text { Drug Adherence }\end{array}$} \\
\hline & (1) & (2) & (3) & (4) & (5) & (6) \\
\hline NonAggr $_{t} \times$ Comp $_{d}$ & $\begin{array}{l}0.017 \\
(0.014) \\
{[0.008]}\end{array}$ & $\begin{array}{l}0.011 \\
(0.014) \\
{[0.009]}\end{array}$ & $\begin{array}{r}-0.017 \\
(0.023) \\
{[0.009]}\end{array}$ & $\begin{array}{r}-0.016 \\
(0.023) \\
{[0.010]}\end{array}$ & $\begin{array}{l}0.086^{* * *} \\
(0.031) \\
{[0.023]}\end{array}$ & $\begin{array}{l}0.085^{* * *} \\
(0.030) \\
{[0.032]}\end{array}$ \\
\hline $\begin{array}{l}\text { Municipality FEs } \\
\text { Month-Year FEs } \\
\text { Covariates }\end{array}$ & $\begin{array}{l}\text { Yes } \\
\text { Yes } \\
\text { No }\end{array}$ & $\begin{array}{l}\text { Yes } \\
\text { Yes } \\
\text { Yes }\end{array}$ & $\begin{array}{l}\text { Yes } \\
\text { Yes } \\
\text { No }\end{array}$ & $\begin{array}{l}\text { Yes } \\
\text { Yes } \\
\text { Yes }\end{array}$ & $\begin{array}{l}\text { Yes } \\
\text { Yes } \\
\text { No }\end{array}$ & $\begin{array}{l}\text { Yes } \\
\text { Yes } \\
\text { Yes }\end{array}$ \\
\hline $\begin{array}{l}\text { Outcome Mean } \\
\text { Observations } \\
\text { Clusters }\end{array}$ & $\begin{array}{c}233.11 \\
4,588 \\
148\end{array}$ & $\begin{array}{c}233.11 \\
4,588 \\
148\end{array}$ & $\begin{array}{c}12.29 \\
4,588 \\
148\end{array}$ & $\begin{array}{c}12.29 \\
4,588 \\
148\end{array}$ & $\begin{array}{c}14.99 \\
4,588 \\
148\end{array}$ & $\begin{array}{c}14.99 \\
4,588 \\
148\end{array}$ \\
\hline
\end{tabular}

Notes: The outcome is the number of inpatient visits in a municipality-month. The results are from Poisson regressions, since the outcome is a count variable. The covariates are census municipality characteristics interacted with year. Standard errors clustered at the municipality level are in parentheses, and spatial standard errors calculated using a $100 \mathrm{~km}$ cutoff window are presented in brackets (Bertanha and Moser 2016). ${ }^{*} p<0.10,{ }^{* *} p<0.05,{ }^{* * *} p<0.01$.

Extortion may impose a large cost on consumers by increasing prices across a range of goods. We highlight that in the case of pharmaceutical drugs, the increase in extortion due to the pact had important downstream effects. The model in Section 3 implies that the effect on consumers may be exacerbated by double-marginalization. While the pact drastically reduced violence, the evidence implies that health was indirectly affected by this increase in prices.

\section{Conclusion}

Policy makers have often resorted to truces to reduce violence between gangs. In this paper, we highlight an additional effect of cooperation between gangs that has largely been ignored. When criminal organizations are able to collude, they significantly increase extortion. We also shed light on the broader economic consequences of extortion: we find that consumers bear a large burden from upstream extortion, given the pass-through to retailers and consumer prices.

The nonaggression pact led to larger price increases for goods with inelastic demand, such as staple foods and many pharmaceutical drugs, implying that extortion may most severely impact poorer households and exacerbate unequal access to healthcare. These results may help reconcile why truces tend to lack popular support or face political backlash. ${ }^{21}$

\footnotetext{
${ }^{21}$ For example, in a public opinion survey, $47 \%$ of Salvadorans said that the 2012 truce mainly benefited the
} 
While we focus primarily on the effect of the 2016 nonaggression pact on one distributor, the results likely have broader implications. Our results suggest a similar increase in prices for pharmaceutical drugs supplied by other distributors, implying that other firms were similarly affected by the pact. Other pacts between criminal organizations, including the 2012 truce in El Salvador, also reduced competition between gangs and may have had similar effects. Understanding the unintended consequences of gang truces is particularly important, given that international organizations have promoted gang pacts in the past. ${ }^{22}$

Extortion is present in many countries; there is a need to develop policies that target the root causes of extortion. We argue that considering the market structure of gangs is important for understanding the level of extortion and the downstream consequences. Our model and findings also suggest that certain goods, such as staple products, are more likely to be affected by extortion, and that protecting these goods from extortion could reduce gang profits and the incentives to compete for territory. Overall, these results show how insights from industrial organization can inform our understanding of criminal organizations and extortion.

\section{References}

Ades, Alberto and Rafael Di Tella, "Rents, Competition, and Corruption," American Economic Review, 1999, 89 (4), 982-993.

Aguilar, Jeannette, Lissette Miranda, Lourdes Hum, Leslie Ramos, Ivan Monzón, Marlon Carranza, and Wendy Lucía Bellanger Rodríguez, Maras y Pandillas en Centroamérica: Las Respuestas de la Sociedad Civil Organizada. Volumen IV, San Salvador, El Salvador: Universidad Centroamericana, 2006.

Amaya, Luis Enrique and Juan José Martínez, "Escisión al Interior de la Pandilla Barrio 18 en El Salvador: Una Mirada Antropológica," Revista Policía y Seguridad Pública, 2015, pp. 149-178.

Amodio, Francesco, Jieun Choi, Giacomo De Giorgi, and Aminur Rahman, "Bribes vs. Taxes: Market Structure and Incentives," Journal of Comparative Economics, 2021.

Angrist, Joshua D and Adriana D Kugler, "Rural Windfall or a New Resource Curse? Coca, Income, and Civil Conflict in Colombia," The Review of Economics and Statistics, 2008, 90 (2), 191-215.

Arkhangelsky, Dmitry, Susan Athey, David A Hirshberg, Guido W Imbens, and Stefan Wager, "Synthetic Difference-in-differences," American Economic Review, 2021, 111 (12), 4088-4118.

Baik, Kyung Hwan, "Difference-form Contest Success Functions and Effort Levels in Contests," European Journal of Political Economy, 1998, 14 (4), 685-701.

Bergquist, Lauren Falcao and Michael Dinerstein, "Competition and Entry in Agricultural Markets: Experimental Evidence from Kenya," American Economic Review, 2020, 110 (12), 3705-47.

Bertanha, Marinho and Petra Moser, "Spatial Errors in Count Data Regressions," Journal of Econometric Methods, 2016, 5 (1), 49-69.

gangs while only $16 \%$ said it benefited the general population (Cawley 2013).

${ }^{22}$ For instance, the Organization of American States supported the 2012 gang truce. 
Blattman, Christopher, Gustavo Duncan, Benjamin Lessing, and Santiago Tobón, "Gang Rule: Understanding and Countering Criminal Governance," 2021. Working Paper.

Bliss, Christopher and Rafael Di Tella, "Does Competition Kill Corruption?," Journal of Political Economy, 1997, 105 (5), 982-993.

Bruhn, Jesse, "Competition in the Black Market: Estimating the Causal Effect of Gangs in Chicago," 2021. Working Paper.

Castillo, Juan Camilo and Dorothy Kronick, "The Logic of Violence in Drug War," American Political Science Review, 2020, pp. 1-14.

Cawley, Marguerite, "Gangs Gain Most from El Salvador Truce: Opinion Poll," 2013. InSight Crime Report.

Che, Yeon-Koo and Ian Gale, "Difference-form Contests and the Robustness of All-pay Auctions," Games and Economic Behavior, 2000, 30 (1), 22-43.

Clark, Robert and Jean-François Houde, "Collusion with Asymmetric Retailers: Evidence from a Gasoline Price-Fixing Case," American Economic Journal: Microeconomics, 2013, 5 (3), 97-123.

_ , Decio Coviello, Jean-François Gauthier, and Art Shneyerov, "Bid Rigging and Entry Deterrence in Public Procurement: Evidence from an Investigation into Collusion and Corruption in Quebec," The Journal of Law, Economics, and Organization, 2018, 34 (3), 301-363.

Clemens, Michael A, "Violence, development, and migration waves: Evidence from Central American child migrant apprehensions," Journal of Urban Economics, 2021, 124, 103355.

Cockayne, James, John de Boer, and Louise Bosetti, "Going Straight: Criminal Spoilers, Gang Truces and Negotiated Transitions to Lawful Order," 2017. United Nations University Centre for Policy Research.

Colella, Fabrizio, Rafael Lalive, Seyhun Orcan Sakalli, and Mathias Thoenig, "Inference with Arbitrary Clustering," 2019.

Conley, Timothy, "GMM Estimation with Cross Sectional Dependence," Journal of Econometrics, 1999, 92, $1-45$.

Correia, Sergio, "Singletons, Cluster-robust Standard Errors and Fixed Effects: A Bad Mix," Technical Note, Duke University, 2015, 7.

Dell, Melissa, "Trafficking Networks and the Mexican Drug War," American Economic Review, 2015, 105 (6), 1738-1779.

Ditta, Elise, “El Salvador Gang Leaders Order End to Killing," 2016. InSight Crime Brief.

Dudley, Steven, “El Salvador's Gang Truce: Positives and Negatives," 2013. InSight Crime Report.

— , Héctor Silva Ávalos, and Juan José Martínez, "MS-13 in the Americas: How the World's Most Notorious Gang Defies Logic, Resist Destruction," InSight Crime, 2018.

Foltz, Jeremy D and Kangli Li, "Competition and Corruption: Highway Corruption in West Africa," Available at SSRN 3956038, 2021.

FUSADES, “Extortiones a la Micro y Pequeña Empresa de El Salvador," 2016. Fundación Salvadoreña para el Desarrollo Económica y Social (FUSADES).

Gagne, David, “Balance de InSight Crime Sobre Homicidios en Latinoamérica en 2015," 2016. InSight Crime Analysis.

Gambetta, Diego, The Sicilian Mafia: The Business of Private Protection, Harvard University Press, 1996.

Garfinkel, Michelle R and Stergios Skaperdas, "Economics of Conflict: An Overview," Handbook of defense economics, 2007, 2, 649-709.

Global Initiative Against Transnational Organized Crime and InSight Crime, "A Criminal Culture: Extortion in Central America," 2019.

Hirshleifer, Jack, "Conflict and Rent-seeking Success Functions: Ratio vs. Difference Models of Relative Success," Public choice, 1989, 63 (2), 101-112. 
Holland, Alisha C, "Right ON Crime? Conservative Party Politics and Mano Dura Policies in El Salvador," Latin American Research Review, 2013, pp. 44-67.

Houde, Jean-François, Terrence Johnson, Molly Lipscomb, and Laura Schechter, "Imperfect Competition and Sanitation: Evidence from Randomized Auctions in Senegal," 2022. Working Paper.

International Crisis Group, "El Salvador's Politics of Perpetual Violence," 2017. Latin America Report $N^{0} 64$.

_ , "Mafia of the Poor: Gang Violence and Extortion in Central America," 2017. Latin America Report $N^{0} 6$.

_ , "Miracle or Mirage? Gangs and Plunging Violence in El Salvador," 2020. Latin America Report $N^{0} 81$.

Kan, Paul Rexton, "Malicious Peace: Violent Criminal Organizations, National Governments and Truces," International Journal of Criminology and Sociology, 2014, 3, 125-132.

Konrad, Kai I and Stergios Skaperdas, "Extortion," Economica, 1998, 65 (260), 461-477.

Levitt, Steven D and Sudhir Alladi Venkatesh, "An Economic Analysis of a Drug-Selling Gang's Finances," The Quarterly Journal of Economics, 2000, 115 (3), 755-789.

Magaloni, Beatriz, Edgar Franco-Vivanco, and Vanessa Melo, "Killing in the Slums: Social Order, Criminal Governance, and Police Violence in Rio de Janeiro," American Political Science Review, 2020, $114(2), 552-572$.

_ , Gustavo Robles, Aila M Matanock, Alberto Diaz-Cayeros, and Vidal Romero, "Living in Fear: The Dynamics of Extortion in Mexico's Drug War," Comparative Political Studies, 2020, 53 (7), 11241174.

Martínez, Carlos, "Gangs Find Common Ground in El Salvador Crackdown," 2016. InSight Crime Analysis.

Martínez, Óscar, Efren Lemus, Carlos Martínez, and Deborah Sontag, "Killers on a Shoestring: Inside the Gangs of El Salvador," The New York Times, 2016.

Melnikov, Nikita, Carlos Schmidt-Padilla, and Maria Micaela Sviatschi, "Gangs, Labor Mobility, and Development," 2020. NBER Working Paper \#27832.

Olken, Benjamin A and Patrick Barron, "The Simple Economics of Extortion: Evidence from Trucking in Aceh," Journal of Political Economy, 2009, 117 (3), 417-452.

Olson, Mancur, "Dictatorship, Democracy, and Development," American political science review, 1993, 87 (3), 567-576.

Papadovassilakis, Alex, “Are El Salvador's Gangs Behind Historic Murder Drop?," 2020. InSight Crime Analysis.

_ and Steven Dudley, "The "Protection Racket," Gangs and Violence in San Salvador," 2020. InSight Crime Investigation.

Peñate Guerra, Margarita Isabel, Kenny Mendoza de Escobar, José Arnulfo Quintanilla Deras, and César Antonio Alvarado Zepeda, "Estimación del Costo Económico de la Violencia en El Salvador 2014," 2016. Departamento de Investigación Económica y Financiera, Banco Central de Reserva de El Salvador.

Roth, Jonathan, "Pretest with Caution: Event-Study Estimates after Testing for Parallel Trends," American Economic Review: Insights, 2022, 4 (3), 305-22.

Seiter, Andreas, A Practical Approach to Pharmaceutical Policy, World Bank Publications, 2010.

Shleifer, Andrei and Robert W Vishny, "Corruption," The Quarterly Journal of Economics, 1993, 108 (3), 599-617.

Skaperdas, Stergios, "Contest Success Functions," Economic Theory, 1996, 7 (2), 283-290.

Spengler, Joseph J, "Vertical Integration and Antitrust Policy," Journal of Political Economy, 1950, 58 (4), 347-352. 
Sviatschi, Maria Micaela, "Making a Narco: Childhood Exposure to Illegal Labor Markets and Criminal Life Paths," Manuscript, Department of Economics, Princeton University, 2018.

_ , "US Criminal Deportations and Human Capital in Central America," in "AEA Papers and Proceedings," Vol. 109 2019, pp. 239-42.

Sviatschi, María Micaela, "Spreading Gangs: Exporting US Criminal Capital to El Salvador," American Economic Review, 2022, 112 (6), 1985-2024.

Tilly, Charles, War Making and State Making as Organized Crime, Routledge, 2017.

Vuković, Siniša and Eric Rahman, "The Gang Truce in El Salvador," 2018. Oxford Research Group.

Weiser, Benjamin, "14 Gang Leaders Directed MS-13 ‘Wave of Death,' U.S. Says," 2021. New York Times.

Yamagiwa, Takayoshi Jose, "El Salvador: The New Law on Medicines and its implementation," 2015. World Health Organization. 


\section{Online Appendix}

\section{A Extortion in El Salvador}

In this section, we provide an overview of extortion and protection and the behavior of gangs in El Salvador. We also discuss how this compares to other countries. We then overview the response by the El Salvador government.

\section{A.1 Extortion Logistics}

The main revenue source for gangs in El Salvador is extortion. This is similar to many criminal organizations in other settings, including the Mafia in Italy, Russia, Japan, China, and the US (Gambetta 1996; Varese et al. 2005; Wang 2013). Protection rackets involve selling security from potential threats. Extortion is often considered a type of protection racket in which the threat comes exclusively from the organization offering protection (Gambetta 1996, 2011). While there are some limited examples of El Salvador gangs offering protection from other threats, the gangs largely engage in straightforward extortion in which they explicitly threaten targets with violence. ${ }^{23}$

A large literature has discussed the parallels between criminal organizations and the state. Both may have a "monopoly of violence" and there are important similarities between extortion collected by gangs and bribes or taxes collected by the state (Olson 1993; Tilly 2017). In an influence book on the Sicilian Mafia, Gambetta (1996) argues that there are limitations to this comparison. Unlike a state, criminal organizations are often independent organizations that sometimes form pacts or cartels. Bribes are paid to government officials to provide a good or service that provides some benefit to the individual. There is at least the possibility that bribes "grease the wheels" and allow scarce government resources to go to those with the highest willingness-to-pay (Lui 1985; Beck and Maher 1986). In contrast, extortion is paid to avoid the threat of violence created by the gang itself, and there is little potentially for an increase in efficiency. This can also be contrasted with taxes, which provide protection from international threats. Finally, Gambetta (1996) points out that gangs maximize profit, whereas the objective of states is often more complicated, especially democratically-elected

\footnotetext{
${ }^{23}$ The gangs often have exclusive territory, thus protecting an extortion target from being extorted by a rival gang in the same location. In this way, the gangs indirectly provide protection from rival gangs.
} 
governments that should serve constituents. In this way, Gambetta (1996) and others argue that gangs are more like individual firms than a state. This latter description of gangs is more in line with descriptions of gangs in El Salvador (e.g. Dudley et al. 2018).

The El Salvador gangs are large organizations with a complex structure that helps maintain territorial control. Both MS-13 and Barrio 18 have national leaders (ranfleros) that often dictate and negotiate larger gang policies, including the 2012 truce and 2016 nonaggression pact. Operations are organized around neighborhood cliques (clicas). A clique, which may comprise ten to hundreds of members, is tied to a set geographic perimeter within a municipality, often a neighborhood (colonia) in urban settings (Dudley et al. 2018). Cliques sends a portion of their extortion revenue to the ranfleros. The ranfleros provide clique members with promotion opportunities, protection to their relatives (inside and outside prisons), and funds for gang operations. Ranfleros leaders also provide coordination across clique territories, help settle disputes, and sanction murders of gang members suspected of cooperating with the police Dudley et al. (2018); Weiser (2021). In large urban areas, such as the capital San Salvador, there are numerous cliques from both MS-13 and Barrio 18. In our context, the delivery firm may pay extortion to multiple cliques from the same gang within one municipality.

Extortion is a complex activity that requires gangs to continually identify potential victims and collect extortion while evading authorities and credibly threatening violence or other repercussions if victims do not pay. In El Salvador, gangs rely on their extensive territorial control - often of whole urban neighborhoods - and an extensive network of collaborators and informants, to identify potential targets, collect information on these targets, and continually collect extortion payments (Dudley et al. 2018; Neu 2019; Global Initiative Against Transnational Organized Crime and InSight Crime 2019). Gangs often invest in a "relationship" with their victims, so they can credibly threaten violence and maintain future extortion payments (Ponce 2021). In an example from sentencing of gang members in El Salvador, extortion victims were sent a WhatsApp message saying that they should pay "otherwise their two children would end up in black bags." The gang member said he "knew where the victim worked, where their children studied, and information on their relatives and that they had no way of escaping." 24 In addition, maintaining the reputation of the gang for following-through on threats is important for ensuring that the threats are credible and victims do not go to the police (Ponce 2021). ${ }^{25}$ The wholesale distributor that

\footnotetext{
${ }^{24}$ The original text comes from sentence 238-3-2018 from the First Court of Sentence in San Salvador available through El Salvador's Judicial Documentation Center (accessed on July 13, 2021).

${ }^{25}$ Since extortion has become a part of daily life in countless neighborhoods in El Salvador, it has also lead to numerous copycats in which opportunistic individuals, usually nongang members, imitate the gangs' extortion tactics (Global Initiative Against Transnational Organized Crime and InSight Crime 2019). However, this is often
} 
is the focus of this paper uses trucks that do not identify the name of the company in order to try to have some anonymity. However, the company told us that certain gang cliques implied they knew where they had their warehouse and could impose a large cost on the firm if they did not agree to extortion demands. For these reasons, collecting extortion is not a trivial task and can require a significant resources and expertise.

Gang extortion and violence tend to be intricately linked (Dudley et al. 2018). Moreover, it's been argued that gangs rationally use violence as a necessary input to collect extortion or engage in other illegal behavior (Gambetta 1996; Castillo and Kronick 2020). Collecting a small extortion payment is relatively low cost since firms might not protest the small fee, and the police would not find it worth their time to go after the gang members. However, demanding higher extortion requires a high threat of violence, which requires resources on the part of the gang (e.g., more members or weapons to credibly threaten violence). Furthermore, as noted above, collecting higher extortion requires closely monitoring firm activities and monitoring (or potentially bribing) police. Additionally, high gang extortion might temp other gangs to try to overtake the territory, further increasing violence.

While there are firms that try to protect themselves from gangs, most firms have a strong incentive to acquiesce. Prior to 2010, there were cases in which the distributor used armored trucks and heavy security details when delivering in gang territory in order to avoid paying extortion. This was an expensive and dangerous approach. Over our period of analysis, the firm set up a security team to monitor regular extortion payments to the gangs, helping ensure the safety of drivers. Other firms in El Salvador often use a similar approach (Martínez et al. 2016).

Finally, we note that trucks are often stopped on a side street prior to a delivery rather than on a main road. This can be contrasted with government bribes such as those analyzed by Olken and Barron (2009). Unlike bribes paid at police checkpoints, the distributor generally pays a single gang to make a delivery given that gangs have exclusive control over a territory.

\section{A.2 Government Responses to Extortion}

The main anti-gang initiative of the government between 2015 and 2019 was Plan Secure El Salvador (PESS). The initiative increased police enforcement and was rolled out in select areas starting in January 2016. PESS targeted a small number of areas and was implemented in three phases. However, phase three was never rolled-out. The program targeted 50 municipalities chosen using proxies of gang presence and crime (Asmann 2018).

less successful than extortion by gangs. 
Additionally, following the pact between gangs, the Sánchez Cerén administration announced a set of "extraordinary measures" in April 2016 that had two main components: a security component, and a prison policy component. The prison policy component was the main component (Lohmuller 2016). The first component regarding security involved a strengthening of the Plan Safe El Salvador (Plan El Salvador Seguro, PESS). In particular, the extraordinary measures increased the number of officers involved in the same municipalities of the first phase of PESS. The measures involved the additional deployment of the elite units, mainly of the Territory Intervention Forces (Fuerzas de Intervención de Territorios, FIRT) and the Immediate Reaction Special Forces (Fuerzas Especiales de Reacción Inmediata, FES), in 10 municipalities concentrated in the Metropolitan Area of San Salvador - the same municipalities intervened by Phase I of PESS. For this reason, we control throughout for the implementation of Plan El Salvador Seguro (PESS). The second component of the extraordinary measures, regarding prison policies, consisted of (i) moving gangs leaders from low risk prisons to maximum security prisons, (ii) eliminating visits to any incarcerated gang member, abd (iii) further reducing access to cellphones or other means of communications near prisons (i.e., the PNC cut electricity for antennas near prisons). This policies were meant to make gang coordination harder to sustain (Lohmuller 2016); however, qualitative evidence suggests that gangs were still able to coordinate and prison leaders were still able to communicate with outsiders and sustain the pact (Ditta 2016; Lohmuller 2018).

\section{B Supporting Data Sources}

\section{B.1 Municipality Characteristics}

We use various sources to construct municipality characteristics that might be correlated with extortion payments. We construct yearly municipality-level measures of nightlight intensity and population density using data from National Oceanic and Atmospheric Administration (2020) and WorldPop (2020), respectively. Additionally, we use the 2007 population census of El Salvador to calculate municipality-level literacy, education, and employment rates (Dirección General de Estadística y Censos 2007). We present summary statistics for these municipality characteristics in Table A-I (Panel C).

\section{B.2 Household Surveys}

From DIGESTYC, we obtained the microdata for the annual household surveys (EHPM) administered between 2014 and 2018. Each year, DIGESTYC surveys around 15 thousand households. The surveys include a comprehensive set of questions related to demographic 
and socioeconomic household characteristics. To measure possible changes in demand, we analyze the information on household income and expenditure per capita. These variables draw from individual-level questions on income and expenditures, and are aggregated to the household level by DIGESTYC.

\section{B.3 Crime Reports}

The homicide data described in Section 2.3 ends in early 2017. We complement it with data from "scene of the crime" reports collected by El Salvador's National Civil Police (PNC) from 2017 to 2019. These reports on homicides differ slightly from the homicide data described in Section 2.3, as the former is recorded as an event happens and the latter is an ex-post recollection. ${ }^{26}$ Aside from this reporting difference, there are no major differences in the data sources: both collect the same variables, including date, time, geographic location, and potential gang involvement. From the PNC, we also obtained event data on other crimes, including theft, robberies, and domestic violence. These data cover the decade from 2010 to 2017 and detail the date and municipality of occurrence.

\section{B.4 Pharmacy Sales}

From the National Directorate of Medicines (DNM), we obtained sales data from pharmacies. There are over 10,000 unique products, defined as a specific molecule-brand-size. Since different size pill packs for the same drug are defined as separate products, we standardize quantity by dividing by the number of pills per pack (or number of milliliters or grams). Drug products are then defined as a molecule-brand. Products that cannot be standardized, constituting 29 percent of the sample, are removed. While the government aimed to collect data from all pharmacies, there were some pharmacies for which the government was not able to obtain data. According to conversations with DNM, these tend to be small or niche pharmacies.

\section{Model Details}

In this section, we provide additional details on the model and derivation of equilibrium violence, extortion, and downstream prices under competition and collusion.

The downstream firm chooses its price (or output quantity) to maximize profit after gang $g$ commits to an extortion rate $e_{g d}$ in municipality $d$. Demand for the good being extorted is

\footnotetext{
${ }^{26}$ Our results hold just using homicide data prior to 2017.
} 
given by $Q_{d}\left(p_{d}\right)=\alpha_{d}-\beta p_{d}$. The first-order condition for the firm, $\frac{\partial \tilde{\pi}_{g d}}{\partial p_{g d}}=0$, implies

$$
p_{g d}^{*}\left(e_{g d}\right)=\frac{1}{2 \beta}\left(\alpha_{d}+\beta e_{g d}\right), \quad q_{g d}^{*}\left(e_{g d}\right)=\frac{1}{2}\left(\alpha_{d}-\beta e_{g d}\right) .
$$

Gangs set the violence level, $h_{g d}$, and the extortion rate, $e_{g d}$, to maximize profit. The share of territory controlled by each gang is given by the contest success function in equation 1 . Gang profits are determined by extortion revenue in their territory, $s_{g d} e_{g d} q_{g d}\left(e_{g d}\right)$, minus cost, given by $\phi h_{g d} e_{g d}$. In general, gangs wish to choose the vector of violence, $\mathbf{h}_{g d}$, and extortion, $\mathbf{e}_{g d}$, in order to maximize discounted profit over an infinite horizon given by

$$
\max _{\mathbf{h}_{g d}, \mathbf{e}_{g d}} \sum_{t=1}^{\infty} \delta^{t-1}\left[\frac{1}{2}\left(\frac{1}{2}+\left(h_{g d t}\right)^{\frac{1}{2}}-\left(h_{-g d t}\right)^{\frac{1}{2}}\right) e_{g d t}\left(\alpha_{d}-\beta e_{g d t}\right)-\phi h_{g d t} e_{g d t}\right] .
$$

where $t$ indexes time and $\delta$ is the discount factor. There is a fixed cost of entry, $F$, for gangs to operate in a municipality. We now consider three cases.

\section{One Gang (Monopoly)}

If variable profit is $\pi_{g d}^{N C}$ when two gangs compete (under the non-collusive equilibrium) in a municipality and $\pi_{g d}^{M}$ when there is only one gang, then a second gang will not wish to enter in a territory when $\pi_{g d}^{N C}-\pi_{g d}^{M}<F$. In this case, there is a monopolist gang that solves

$$
\max _{h_{g d}, e_{g d}}\left(e_{g d}\left(\alpha_{d}-\beta e_{g d}\right)-\phi h_{g d} e_{g d}\right) .
$$

Noting that it is optimal for the gang to set $h_{g d}=0$ and considering the first-order condition (FOC) with respect to extortion, it is optimal for the gang to charge extortion rate $\frac{\alpha_{d}}{2 \beta}$. Substituting the extortion rate into equation $A-1$, downstream prices are $\frac{3 \alpha_{d}}{4 \beta}$. This can be compared to downstream prices without extortion, given by $\frac{\alpha_{d}}{2 \beta}$. Profits of the gang in this case are given by $\pi_{g d}^{M}=\frac{\alpha_{d}^{2}}{8 \beta}$.

\section{Competitive Equilibrium with Two Gangs}

Now consider the case in which $\pi_{g d}^{N C}-\pi_{g d}^{M}>F$, so there are two gangs that can profitable enter a municipality. We start by examining the case in which the two gangs compete. In a period in which a gang chooses violence and extortion, profits are given in equation 2.

First, we consider the FOC with respect to violence given by

$$
\frac{1}{4} h_{g d}^{-1 / 2} e_{g d}\left(\alpha_{d}-\beta e_{g d}\right)-\phi e_{g d}=0
$$


which implies

$$
h_{g d}=\left(\frac{\alpha_{d}-\beta e_{g d}}{4 \phi}\right)^{2} .
$$

The FOC with respect to extortion is

$$
\frac{1}{2}\left(\frac{1}{2}+\left(h_{g d}\right)^{\frac{1}{2}}-\left(h_{-g d}\right)^{\frac{1}{2}}\right) \alpha_{d}-\left(\frac{1}{2}+\left(h_{g d}\right)^{\frac{1}{2}}-\left(h_{-g d}\right)^{\frac{1}{2}}\right) \beta e_{g d}-\phi h_{g d}=0
$$

Solving the FOC and noting that gangs are symmetric, and therefore $h_{g d}=h_{-g d}$, implies that extortion is given by

$$
e_{g d}=\frac{\alpha_{d}-4 \phi h_{g d}}{2 \beta}
$$

Substituting equation $\mathrm{A}_{-5}$ into the above, we obtain the equilibrium extortion rate given by

$$
e_{g d}^{N C}=\frac{2 \sqrt{4 \phi^{2}-\alpha_{d} \phi}+\alpha_{d}-4 \phi}{\beta} .
$$

Substituting this into equation $A-5$ and equation $A-1$, we find the equilibrium violence and downstream prices. These are given by

$$
h_{g d}^{N C}=\frac{\left(4 \phi-2 \sqrt{4 \phi^{2}-\alpha_{d} \phi}\right)^{2}}{16 \phi^{2}}
$$

and

$$
p_{g d}^{N C}=\frac{2 \sqrt{4 \phi^{2}-\alpha_{d} \phi}+2 \alpha_{d}-4 \phi}{2 \beta} .
$$

Note that we assume $\phi>\frac{\alpha_{d}}{4}$ such that the solution is well-behaved.

Gang profits under competition can be obtained by substituting equation A- 8 and equation A-9 into equation 2 and are given by

$$
\pi_{g d}^{N C}=\frac{\left(2 \sqrt{4 \phi^{2}-\alpha_{d} \phi}+\alpha_{d}-4 \phi\right)^{2}}{4 \beta} .
$$

This implies there is threshold $\alpha_{d}^{c}$ such that $\pi_{g d}^{N C}-\pi_{g d}^{M}<F$ for $\alpha_{d}<\alpha_{d}^{c}$.

\section{Collusive Equilibrium with Two Gangs}

If identical gangs collude and maximize joint profit then they split the market in each mu-

nicipality $\left(s_{g d}=\frac{1}{2}\right)$ and do not need to use violence $\left(h_{g d}=0\right)$. Collusive profits for gang $g$ 
are given by

$$
\pi_{g d}^{C}=\frac{1}{4} e_{g d}\left(\alpha_{d}-\beta e_{g d}\right)
$$

The first-order condition, $\frac{\partial \pi_{g d}^{C}}{\partial e_{g d}}=0$, implies $e_{g d}^{C}=\frac{\alpha_{d}}{2 \beta}$, the same as the case with a monopolist gang. This results in gang profits of $\frac{\alpha_{d}^{2}}{16 \beta}$.

Compared to the case in which gangs compete, gang collusion decreases violence. The decrease in violence is given by equation A-9. Collusion increases extortion by

$$
\frac{1}{2 \beta}(8 \phi-4 \sqrt{\phi} \sqrt{4 \phi-\alpha}-\alpha)
$$

and increases downstream prices by

$$
\frac{1}{4 \beta}\left(8 \phi-4 \sqrt{\phi} \sqrt{4 \phi-\alpha_{d}}-\alpha_{d}\right)
$$

Furthermore, gang profits under collusion increase by

$$
\frac{\alpha_{d}^{2}-4\left(2 \sqrt{\phi} \sqrt{4 \phi-\alpha_{d}}+\alpha_{d}-4 \phi\right)^{2}}{16 \beta} .
$$

We note that a feature of the model is double-marginalization, a coordination failure that arises in vertical markets when a downstream firm and upstream firm have market power and set margins independently (Spengler 1950). Double marginalization implies that downstream prices are higher than what would be set by gangs if they set prices directly. Consequently, double marginalization induces deadweight loss from extortion, especially when gangs collude. It is well known that double-marginalization can be eliminated using non-linear pricing, however the literature has identified a number of reasons why non-linear pricing may be difficult in practice. The gang could theoretically charge a single annual fixed fee equal to the downstream firm's profit, however this is not seen in practice.

\section{Additional Figures and Tables}


Table A-1

Summary Statistics for Pharmacies, Hospital Visits, and Municipality Characteristics

\begin{tabular}{|c|c|c|c|c|}
\hline & Mean & SD & Min & Max \\
\hline \multicolumn{5}{|l|}{ Panel A. Pharmacy sales by drug-pharmacy-month: } \\
\hline Revenue (all pharmacies) & 20.7 & 61.4 & 0.0 & 16,171 \\
\hline Cost (all pharmacies) & 4.0 & 36.9 & 0.0 & 11,703 \\
\hline Price (all pharmacies) & 14.5 & 20.2 & 0.0 & 2,620 \\
\hline Revenue (pharmacies supplied by distributer) & 19.8 & 65.3 & 0.0 & 13,894 \\
\hline Cost (pharmacies supplied by distributer) & 3.8 & 33.1 & 0.0 & 6,596 \\
\hline Price (pharmacies supplied by distributer) & 14.3 & 20.9 & 0.0 & 2,446 \\
\hline Unique pharmacies & \multicolumn{4}{|c|}{323} \\
\hline Unique drugs & \multicolumn{4}{|c|}{10,756} \\
\hline Total observations & \multicolumn{4}{|c|}{$1,935,960$} \\
\hline \multicolumn{5}{|l|}{ Panel B. Hospital visits by municipality-month: } \\
\hline Hospital visits & 143 & 225 & 1 & 2,314 \\
\hline Hospital visits (injuries) & 8 & 12 & 0 & 106 \\
\hline Hospital visits (diabetes) & 4 & 8 & 0 & 115 \\
\hline Hospital visits (respiratory) & 1 & 2 & 0 & 52 \\
\hline Hospital visits (hypertension) & 2 & 4 & 0 & 39 \\
\hline Hospital visits (coronary) & 1 & 2 & 0 & 40 \\
\hline Total observations & \multicolumn{4}{|c|}{18,611} \\
\hline \multicolumn{5}{|l|}{ Panel C. Municipality characteristics: } \\
\hline Nightlights & 0.86 & 2.11 & 0 & 17 \\
\hline Population density & 4.21 & 9.04 & 0 & 64 \\
\hline Literate share $(\%)$ & 91.35 & 5.10 & 77 & 100 \\
\hline Educated & 1.51 & 0.07 & 1 & 2 \\
\hline Employed share (\%) & 28.61 & 9.70 & 3 & 52 \\
\hline Total observations & \multicolumn{4}{|c|}{263} \\
\hline
\end{tabular}

Notes: All revenues, costs, and payments are reported in US dollars. Sample period is 6/2015 to 12/2017. In Panel A, minimum values are rounded to the nearest \$o.1.

Figure A-1

Example Routes, Deliveries, \& Extortion Payments on a Single Day

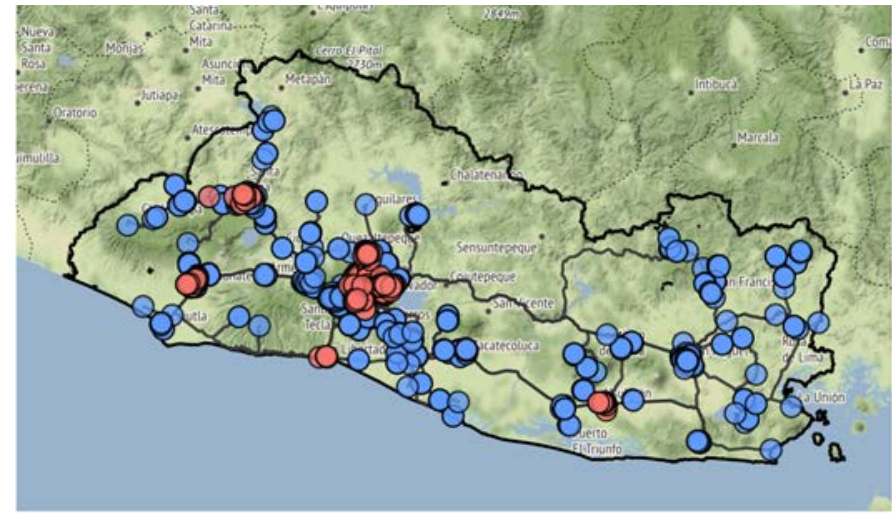

Delivery Routes

- Route

Stop Type

○ Delivery

Delivery \& Extortion

Notes: Map shows example of all truck routes, deliveries to retailers, and extortion payments to gangs on a single day in December, 2016. 
Figure A-2

Extortion, Homicides, and Gang Competition Across Municipalities

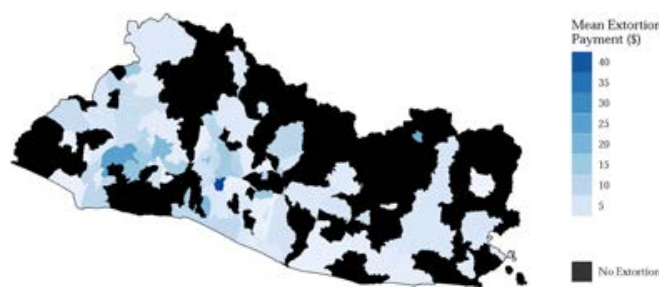

Panel A. Average Extortion Payment

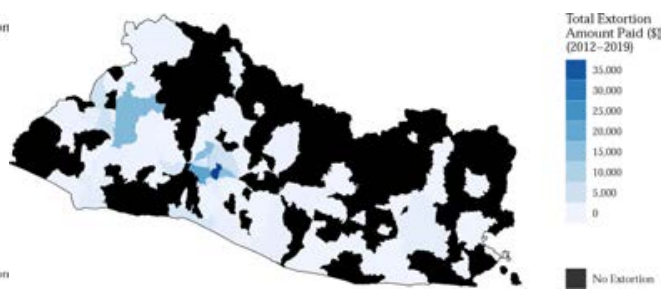

Panel B. Total Extortion

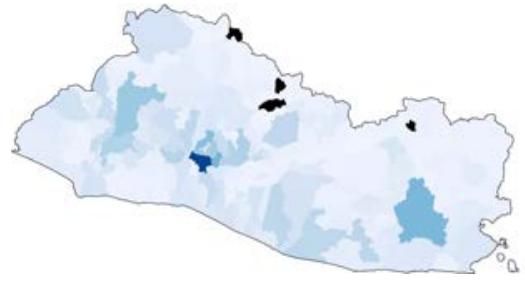

Panel C. Yearly Homicides
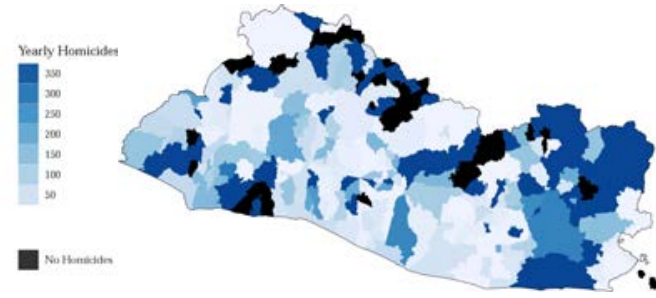

Panel D. Gang HHI

Notes: Gang HHI defined using MS-13 and Barrio-18 homicides.

Figure A-3

Delivery Frequencies and Values Across Municipalities

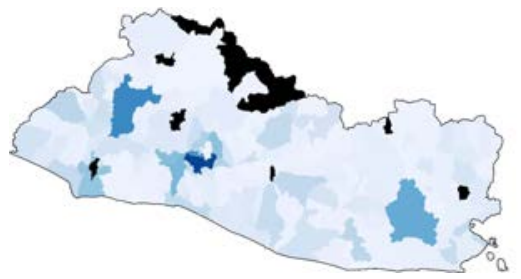

Panel A. Number of Deliveries

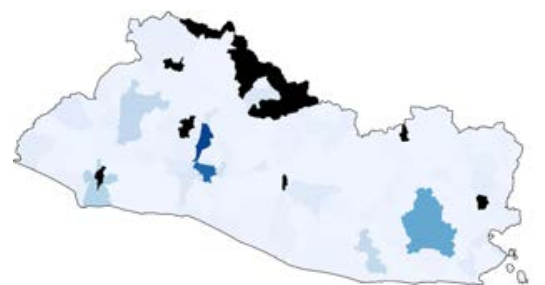

Panel C. Total Delivery Value

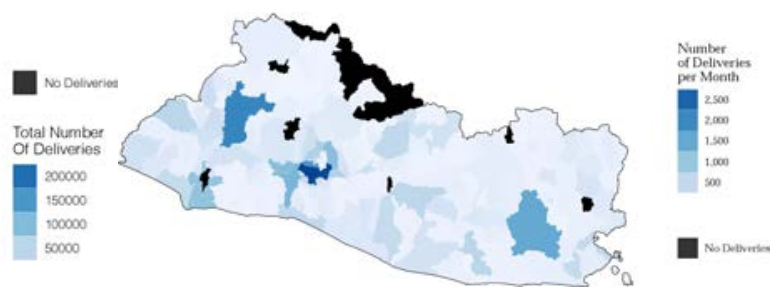

Panel B. Deliveries Per Month

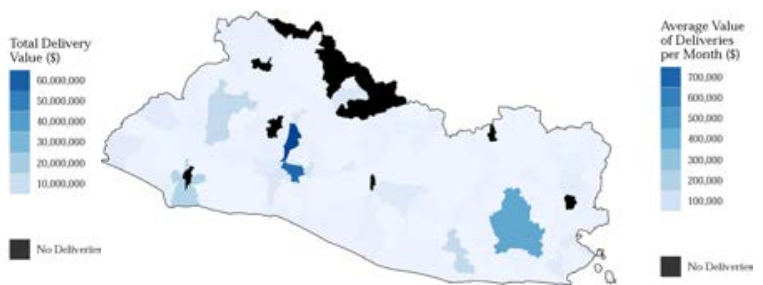

Panel D. Monthly Delivery Value

Notes: Data is from 2012-2019. 
Table A-2

Relationship between Extortion and Delivery Values

\begin{tabular}{lcccc}
\hline & $\log$ (Extortion) & $\log$ (Extortion) & $\log$ (Extortion) & $\log$ (Extortion) \\
\hline $\log$ (Value of Delivery) & $0.040^{* *}$ & $0.023^{* *}$ & $0.014^{*}$ & $0.022^{* * *}$ \\
& $(0.017)$ & $(0.011)$ & $(0.008)$ & $(0.006)$ \\
Municipality FEs & & & & Yes \\
Route FEs & No & Yes & Yes & Yes \\
Retailer FEs & No & No & Yes & Yes \\
\hline Outcome Mean & No & No & No & 1.65 \\
Adjusted R2 & 1.66 & 1.66 & 1.66 & 0.5444 \\
Observations & 0.0013 & 0.1889 & 0.3630 & 59,965 \\
Clusters & 62,798 & 62,787 & 62,783 & 113 \\
\hline
\end{tabular}

Notes: The unit of observation is a delivery on a route. Standard errors clustered at the route level in parentheses. ${ }^{*} p<0.10,{ }^{* *} p<0.05,{ }^{* * *} p<0.01$.

Figure A-4

Histogram of Homicide HHI prior to Nonaggression Pact

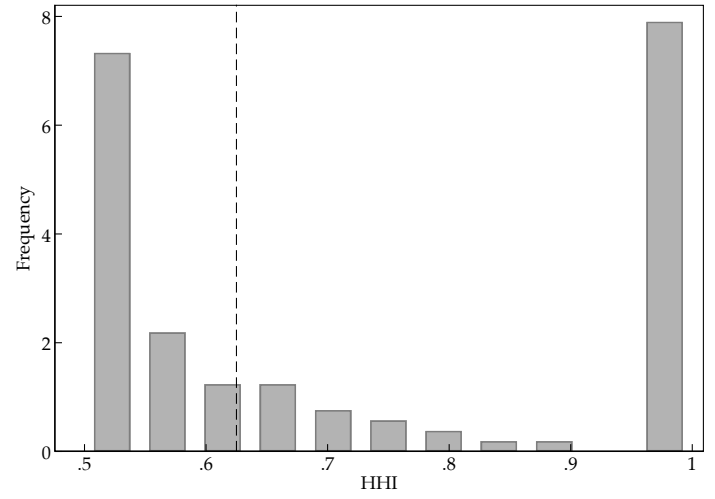

Panel A. Municipality level

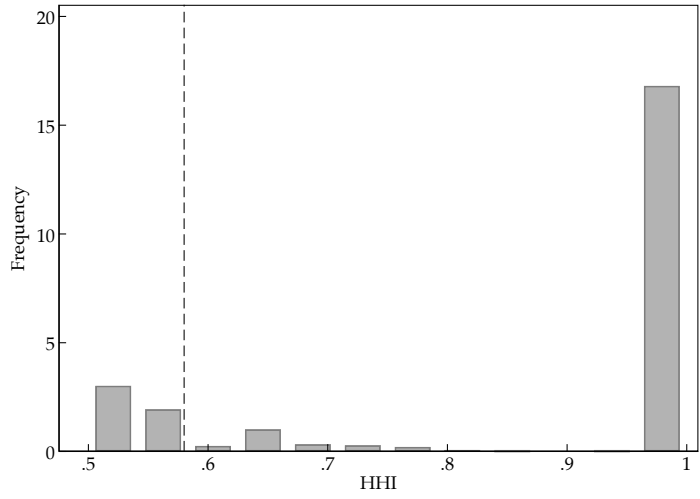

Panel B. Canton level

Notes: Vertical line shows preferred cutoff for defining areas with competition. 
Figure A-5

Correlation between Homicide HHI and Inmate HHI

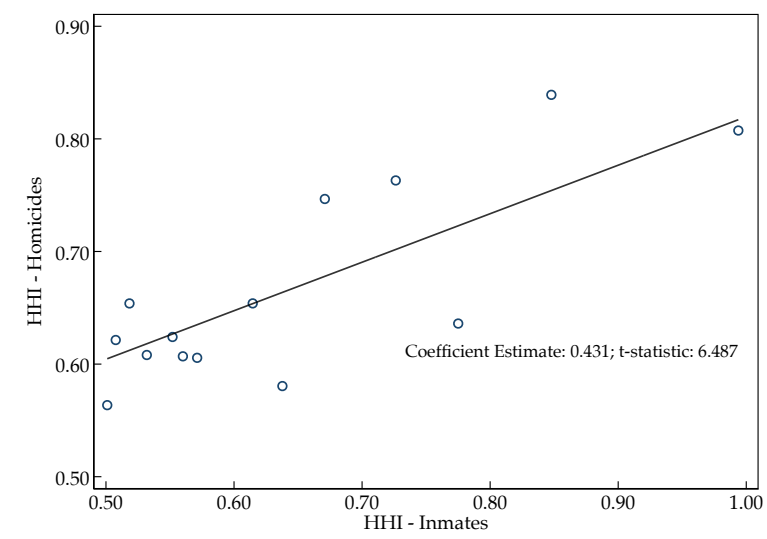

Figure A-6

Relationship Between Extortion Rates and Number of Extortion Payments

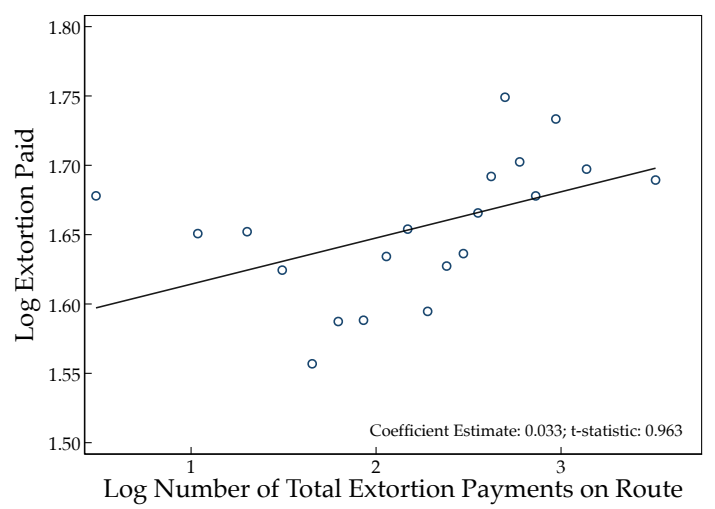

Notes: The figure presents binscatters between the log of the extortion amount paid by the firm upon delivery and the log number of extortion payments made on a route on the same day. The unit of observation is an extortion payment-delivery pair. The regressions include route fixed effects. The bottom-right of each figure presents the estimated coefficient and t-statistic. Standard errors are clustered at the delivery route level. 
Table A-3

Effect of Nonaggression Pact on Crime

in Municipalities with Gang Competition

\begin{tabular}{|c|c|c|c|c|}
\hline & $\begin{array}{c}\text { Gang } \\
\text { Homicides }\end{array}$ & Theft & Robbery & $\begin{array}{l}\text { Domestic } \\
\text { Violence }\end{array}$ \\
\hline & (1) & (2) & (3) & (4) \\
\hline $\operatorname{NonAggr}_{t} \times$ Comp $_{d}$ & $\begin{array}{c}-0.321^{* *} \\
(0.141) \\
{[0.137]}\end{array}$ & $\begin{array}{r}-0.160 \\
(0.354) \\
{[0.355]}\end{array}$ & $\begin{array}{c}-0.180 \\
(0.225) \\
{[0.212]}\end{array}$ & $\begin{array}{c}0.111 \\
(0.634) \\
{[0.650]}\end{array}$ \\
\hline Municipality FEs & Yes & Yes & Yes & Yes \\
\hline Month-Year FEs & Yes & Yes & Yes & Yes \\
\hline Outcome Mean & 0.86 & 0.38 & 0.28 & 0.17 \\
\hline Observations & 3,872 & 3,534 & 3,441 & 3,472 \\
\hline
\end{tabular}

Notes: The unit of observation is a municipality-month. Gang homicides includes the sample of homicides in which MS-13 or Barrio 18 was a perpetrator or victim. The sample period is $6 / 2015$ to $1 / 2018$. Results from Poisson regressions. Municipalities in which the outcome is zero for all periods are dropped. Covariates include 2007 census municipality characteristics - literacy, education, employment - interacted with year, and control for the implementation of Plan El Salvador Seguro (PESS). Standard errors clustered at the municipality level in parentheses and Conley (1999) standard errors calculated using a $100 \mathrm{~km}$ cut-off window are presented in brackets. ${ }^{*} p<0.10,{ }^{* *} p<0.05,{ }^{* * *} p<0.01$. 
Figure A-7

Impact of Nonaggression Pact on Sales

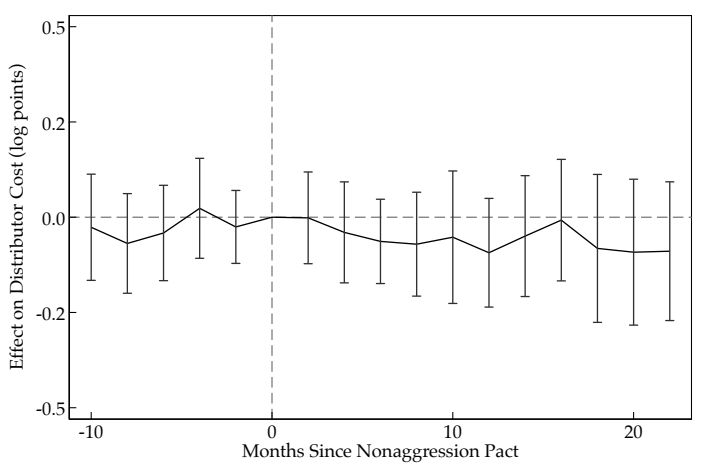

Panel A. Total cost

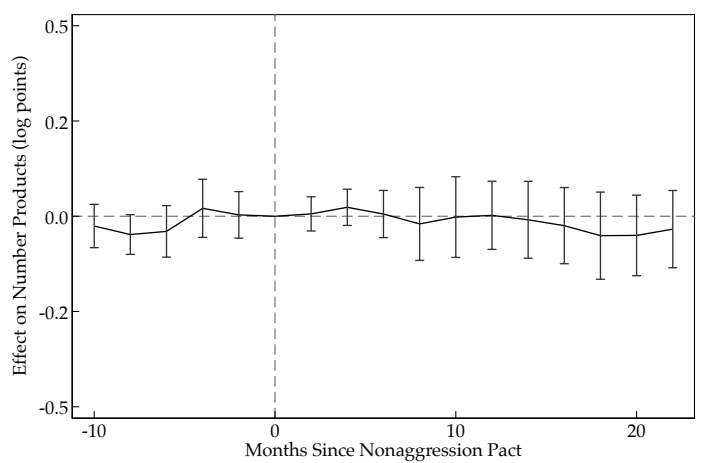

Panel C. Unique products

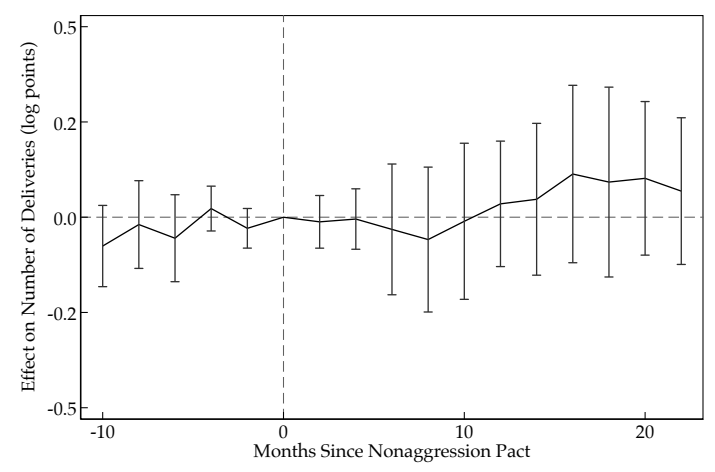

Panel B. Total deliveries

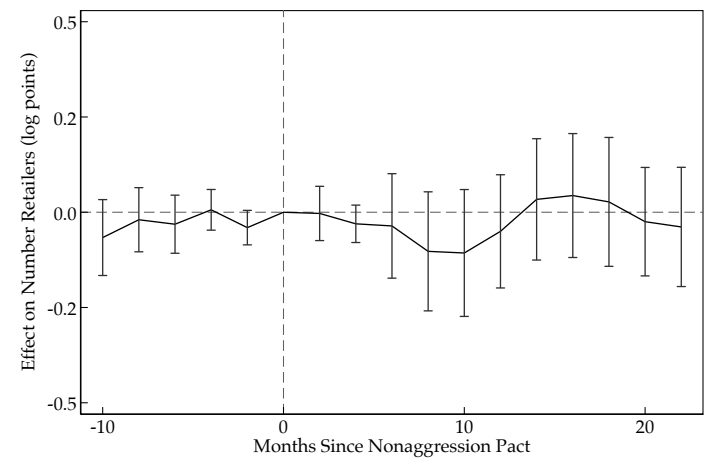

Panel D. Unique retailers

Notes: Vertical line shows start of nonaggression pact (April 2016). Panel A and B show bimonthly point estimates from the difference-in-difference specification with log total cost and $\log$ total trips by municipality-route-month as the outcome. Panel C and D show the results with the number of products and number of retailers by municipality-route-month as the outcome. Specification includes month fixed effects, municipality-route fixed effects, and controls for census municipality characteristics interacted with year. The period prior to the start of the nonaggression pact is omitted. Estimates from OLS regression for cost and deliveries and Poisson regression for count outcomes. Error bars indicate $95 \%$ confidence intervals using standard errors clustered at the municipality level. 
Figure A-8

Impact of Nonaggression Pact on Delivery Routes

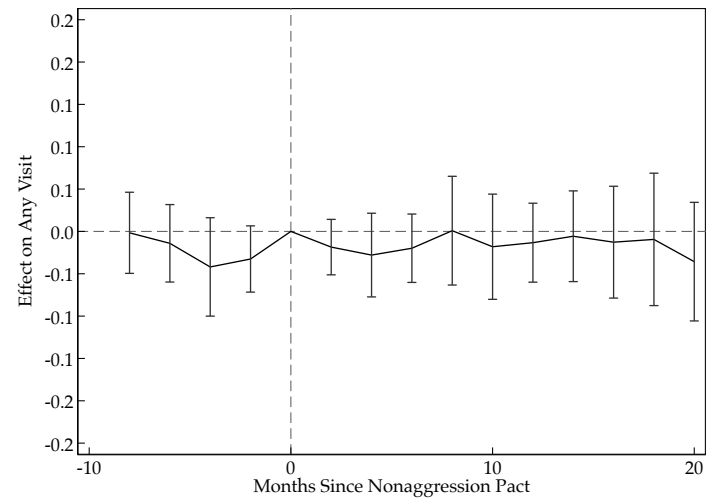

Panel A. Any Visit

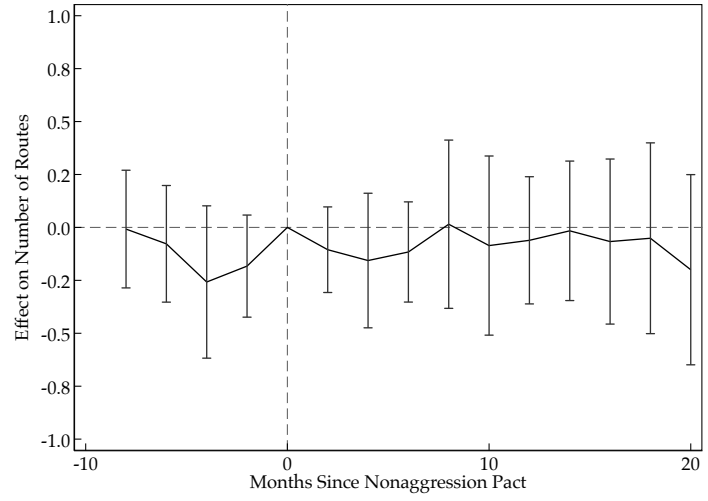

Panel B. Number of Routes

Notes: Vertical line shows start of nonaggression pact (April 2016). Shows bimonthly point estimates using the difference-in-difference specification. The unit of observation in Panel A is a municipalityroute-month, where the sample is comprised of all municipality-routes ever visited by the firm during the sample period. The outcome in Panel A is an indicator equal to 1 if the firm made a delivery in a municipality-route-month; specification includes month, municipality, and route fixed effects. The unit of observation in Panel B is a municipality-month, and the sample is comprised of all municipality-routes ever visited by the firm during the sample period. The outcome in Panel B is the number of routes by the firm that made visits to a municipality-month; specification includes month fixed effects and municipality fixed effects. The period prior to the start of the nonaggression pact is omitted. Error bars indicate $95 \%$ confidence intervals using standard errors clustered at the municipality level. 
Table A-4

Effect of Nonaggression Pact on Extensive Margin of Extortion

\begin{tabular}{|c|c|c|c|c|c|c|}
\hline & \multicolumn{6}{|c|}{ Panel A: Outcome: Has Extortion } \\
\hline & $(1)$ & $(2)$ & (3) & (4) & (5) & (6) \\
\hline NonAggr $_{t} \times$ Comp $_{d}$ & $\begin{array}{c}0.003 \\
(0.033) \\
{[0.026]}\end{array}$ & $\begin{array}{c}0.003 \\
(0.017) \\
{[0.024]}\end{array}$ & $\begin{array}{c}0.002 \\
(0.027) \\
{[0.022]}\end{array}$ & $\begin{array}{c}0.008 \\
(0.030) \\
{[0.026]}\end{array}$ & $\begin{array}{c}0.007 \\
(0.017) \\
{[0.023]}\end{array}$ & $\begin{array}{c}0.006 \\
(0.030) \\
{[0.022]}\end{array}$ \\
\hline PESS $_{\mathrm{dt}}$ & & & & $\begin{array}{l}1.198^{* * *} \\
(0.073) \\
{[0.067]}\end{array}$ & $\begin{array}{l}1.092^{* * *} \\
(0.089) \\
{[0.064]}\end{array}$ & $\begin{array}{l}1.048^{* * *} \\
(0.091) \\
{[0.064]}\end{array}$ \\
\hline Month-Year FEs & Yes & Yes & Yes & Yes & Yes & Yes \\
\hline Municipality FEs & Yes & No & No & Yes & No & No \\
\hline Route FEs & Yes & No & No & Yes & No & No \\
\hline Municipality-Route FEs & No & Yes & Yes & No & Yes & Yes \\
\hline Route-NonAggr $\mathrm{r}_{\mathrm{t}}$ FEs & No & No & Yes & No & No & Yes \\
\hline \multirow{4}{*}{$\begin{array}{l}\text { Outcome Mean } \\
\text { Observations }\end{array}$} & 0.18 & 0.18 & 0.18 & 0.18 & 0.18 & 0.18 \\
\hline & 12,847 & 12,847 & 12,847 & 12,847 & 12,847 & 12,847 \\
\hline & \multicolumn{6}{|c|}{ Panel B: Outcome: $\log ($ Number of Extortion Payments+1) } \\
\hline & $(1)$ & $(2)$ & (3) & (4) & (5) & $(6)$ \\
\hline NonAggr $_{t} \times$ Comp $_{d}$ & $\begin{array}{c}-0.004 \\
(0.062) \\
{[0.050]}\end{array}$ & $\begin{array}{r}-0.004 \\
(0.027) \\
{[0.044]}\end{array}$ & $\begin{array}{c}-0.025 \\
(0.049) \\
{[0.047]}\end{array}$ & $\begin{array}{l}0.003 \\
(0.058) \\
{[0.048]}\end{array}$ & $\begin{array}{l}0.002 \\
(0.031) \\
{[0.042]}\end{array}$ & $\begin{array}{c}-0.018 \\
(0.055) \\
{[0.046]}\end{array}$ \\
\hline $\mathrm{PESS}_{\mathrm{dt}}$ & & & & $\begin{array}{l}2.020^{* * *} \\
(0.193) \\
{[0.189]}\end{array}$ & $\begin{array}{l}1.722 \text { *** } \\
(0.229) \\
{[0.166]}\end{array}$ & $\begin{array}{l}1.637^{* * *} \\
(0.227) \\
{[0.159]}\end{array}$ \\
\hline Month-Year FEs & Yes & Yes & Yes & Yes & Yes & Yes \\
\hline Municipality FEs & Yes & No & No & Yes & No & No \\
\hline Route FEs & Yes & No & No & Yes & No & No \\
\hline Municipality-Route FEs & No & Yes & Yes & No & Yes & Yes \\
\hline Route-NonAggr $r_{t}$ FEs & No & No & Yes & No & No & Yes \\
\hline Outcome Mean & 0.29 & 0.29 & 0.29 & 0.29 & 0.29 & 0.29 \\
\hline Observations & 12,847 & 12,847 & 12,847 & 12,847 & 12,847 & 12,847 \\
\hline
\end{tabular}

Notes: The unit of observation is a route-municipality-month. The outcome variable in Panel $\mathrm{A}$ is an indicator variable equal to one if a route-municipality-month paid any extortion, and zero otherwise. The outcome variable in Panel B is the log of the number of extortion payments made in a route-municipality-month. The sample period is $6 / 2015$ to $1 / 2018$. The sample is a balanced panel comprised of all municipality-routes ever visited by the firm during the sample period. PESS $d t$ is an indicator variable equal to one if the municipality was part of Plan Secure El Salvador (PESS) at month $t$ and zero otherwise. Regressions drop "singleton" groups when including additional fixed effects (Correia 2015). Covariates include census municipality characteristics - literacy, educational attainment, employment - interacted with year. Standard errors clustered at the municipality level in parentheses and Conley (1999) standard errors calculated using a $100 \mathrm{~km}$ cut-off window with a 20-month temporal auto-correlation window are presented in brackets (Colella et al. 2019). ${ }^{*} p<0.10,{ }^{* *} p<0.05,{ }^{* * *} p<0.01$. 
Table A-5

Effect of Nonaggression Pact on Arrests for Threats

\begin{tabular}{|c|c|c|c|}
\hline & $\begin{array}{c}\text { All } \\
\text { Threats }\end{array}$ & $\begin{array}{c}\text { Gang-related } \\
\text { Threats }\end{array}$ & $\begin{array}{c}\text { nongang related } \\
\text { Threats }\end{array}$ \\
\hline & (1) & (2) & (3) \\
\hline $\operatorname{NonAggr}_{t} \times$ Comp $_{d}$ & $\begin{array}{c}-0.010 \\
(0.095) \\
{[0.094]}\end{array}$ & $\begin{array}{c}0.844^{* *} \\
(0.421) \\
{[0.417]}\end{array}$ & $\begin{array}{r}-0.082 \\
(0.097) \\
{[0.097]}\end{array}$ \\
\hline Municipality FEs & Yes & Yes & Yes \\
\hline Month-Year FEs & Yes & Yes & Yes \\
\hline Outcome Mean & 1.21 & 0.10 & 1.11 \\
\hline Observations & 4,495 & 2,945 & 4,495 \\
\hline Clusters & 145 & 95 & 145 \\
\hline
\end{tabular}

Notes: The unit of observation is a municipality-month. The outcome is the number of arrests for threats ("amenazas") in a municipality-month. Results from Poisson regressions. The sample period is $6 / 2015$ to $1 / 2018$. Municipalities in which the outcome is zero for all periods are dropped. Regressions drop "singleton" groups when including additional fixed effects (Correia 2015). Covariates include 2007 census municipality characteristics - literacy, education, employment - interacted with year, and control for the implementation of Plan El Salvador Seguro (PESS). Standard errors clustered at the municipality level in parentheses and Conley (1999) standard errors calculated using a $100 \mathrm{~km}$ cut-off window are presented in brackets. ${ }^{*} p<0.10$, ${ }^{* *} p<0.05,{ }^{* * *} p<0.01$.

Table A-6

Effect of Nonaggression Pact on Price Discrimination by Gangs

\begin{tabular}{lcc}
\hline & $\log$ (Extortion) & $\log ($ Extortion $)$ \\
\hline NonAggr $_{\mathrm{t}} \times$ Comp $_{\mathrm{d}}$ & 0.090 & $0.289^{* * *}$ \\
& $(0.103)$ & $(0.089)$ \\
& {$[0.067]$} & {$[0.082]$} \\
NonAggr $_{\mathrm{t}} \times$ Comp $_{\mathrm{d}} \times$ Value $_{\mathrm{r}}$ & $0.125^{* *}$ & $0.131^{* * *}$ \\
& $(0.058)$ & $(0.033)$ \\
& {$[0.048]$} & {$[0.039]$} \\
Municipality FEs & Yes & Yes \\
Month-Year FEs & Yes & Yes \\
Route FEs & No & Yes \\
\hline Outcome Mean & 1.59 & 1.59 \\
Adjusted R2 & 0.283 & 0.375 \\
Observations & 36,810 & 36,807 \\
\hline
\end{tabular}

Notes: The unit of observation is an extortion payment. Value $\mathrm{r}_{\mathrm{r}}$ is the value of deliveries for retailer $r$ in $\$ 1$,ooos. The sample period is 6/2015 to $1 / 2018$. Standard errors clustered at the municipality level in parentheses and Conley (1999) standard errors calculated using a $100 \mathrm{~km}$ cut-off window with a 20-month temporal auto-correlation window are presented in brackets (Colella et al. 2019). ${ }^{*} p<0.10,{ }^{* *} p<0.05,{ }^{* * *} p<0.01$. 
Table A-7

Effect of Nonaggression Pact on Time between Extortion Payments

\begin{tabular}{lcc}
\hline & Delivery Time & Delivery Time \\
\hline NonAggr $_{\mathrm{t}} \times$ Comp $_{\mathrm{d}}$ & 7.014 & $6.465^{* *}$ \\
& $(4.868)$ & $(2.838)$ \\
& {$[3.016]$} & {$[2.538]$} \\
Municipality FEs & Yes & Yes \\
Month-Year FEs & Yes & Yes \\
Route FEs & No & Yes \\
\hline Outcome Mean & 59.95 & 59.95 \\
Adjusted R2 & 0.109 & 0.120 \\
Observations & 7,781 & 7,777 \\
\hline
\end{tabular}

Notes: The unit of observation is an extortion payment. The dependent variable is the time between extortion payments in minutes as recorded by the wholesaler. The sample period is $6 / 2015$ to $1 / 2018$. Standard errors clustered at the municipality level in parentheses and Conley (1999) standard errors calculated using a $100 \mathrm{~km}$ cut-off window with a 20-month temporal auto-correlation window are presented in brackets (Colella et al. 2019). ${ }^{*} p<0.10,{ }^{* *} p<0.05,{ }^{* * *} p<0.01$.

Table A-8

Effect of Nonaggression Pact on

Development, Population, Household Incomes, and Household Expenditures

\begin{tabular}{|c|c|c|c|c|c|c|c|c|}
\hline & $\begin{array}{l}\text { Nightlight } \\
\text { Intensity }\end{array}$ & $\begin{array}{l}\log \text { (Nightlight } \\
\text { Intensity) }\end{array}$ & $\begin{array}{l}\text { Population } \\
\text { Density }\end{array}$ & $\begin{array}{c}\log \text { (Population } \\
\text { Density) }\end{array}$ & $\begin{array}{l}\text { Household } \\
\text { Income }\end{array}$ & $\begin{array}{c}\text { Income } \\
\text { Per Capita }\end{array}$ & $\begin{array}{l}\text { Household } \\
\text { Expenditure }\end{array}$ & $\begin{array}{l}\text { Expenditure } \\
\text { Per Capita }\end{array}$ \\
\hline NonAggr $_{t} \times$ Comp $_{d}$ & $\begin{array}{c}0.003 \\
(0.053) \\
{[0.070]}\end{array}$ & $\begin{array}{c}-0.030 \\
(0.020) \\
{[0.020]}\end{array}$ & $\begin{array}{c}-0.048 \\
(0.101) \\
{[0.113]}\end{array}$ & $\begin{array}{c}-0.003 \\
(0.007) \\
{[0.007]}\end{array}$ & $\begin{array}{l}-4.787 \\
(18.206) \\
{[17.416]}\end{array}$ & $\begin{array}{c}-2.056 \\
(8.357) \\
{[8.386]}\end{array}$ & $\begin{array}{c}7.092 \\
(7.864) \\
{[6.971]}\end{array}$ & $\begin{array}{l}2.607 \\
(2.607) \\
{[2.551]}\end{array}$ \\
\hline $\begin{array}{l}\text { Municipality FEs } \\
\text { Year FEs }\end{array}$ & $\begin{array}{l}\text { Yes } \\
\text { Yes }\end{array}$ & $\begin{array}{l}\text { Yes } \\
\text { Yes }\end{array}$ & $\begin{array}{l}\text { Yes } \\
\text { Yes }\end{array}$ & $\begin{array}{l}\text { Yes } \\
\text { Yes }\end{array}$ & $\begin{array}{l}\text { Yes } \\
\text { Yes }\end{array}$ & $\begin{array}{l}\text { Yes } \\
\text { Yes }\end{array}$ & $\begin{array}{l}\text { Yes } \\
\text { Yes }\end{array}$ & $\begin{array}{l}\text { Yes } \\
\text { Yes }\end{array}$ \\
\hline $\begin{array}{l}\text { Outcome Mean } \\
\text { Adjusted R2 } \\
\text { Observations } \\
\text { Clusters }\end{array}$ & $\begin{array}{l}1.32 \\
0.99 \\
740 \\
148\end{array}$ & $\begin{array}{c}-0.41 \\
0.99 \\
740 \\
148\end{array}$ & $\begin{array}{l}6.21 \\
1.00 \\
740 \\
148\end{array}$ & $\begin{array}{l}1.08 \\
1.00 \\
740 \\
148\end{array}$ & $\begin{array}{c}492.30 \\
0.69 \\
666 \\
136\end{array}$ & $\begin{array}{c}152.56 \\
0.66 \\
666 \\
136\end{array}$ & $\begin{array}{c}331.24 \\
0.81 \\
666 \\
136\end{array}$ & $\begin{array}{c}102.90 \\
0.83 \\
666 \\
136\end{array}$ \\
\hline
\end{tabular}

Notes: The unit of observation is a municipality-year. The sample period is 2014 to 2018. Standard errors clustered at the municipality level in parentheses and Conley (1999) standard errors calculated using a $100 \mathrm{~km}$ cut-off window with a 20-month temporal auto-correlation window are presented in brackets (Colella et al. 2019). ${ }^{*} p<0.10,{ }^{* *} p<0.05,{ }^{* * *} p<0.01$. 
Table A-9

Effect of Nonaggression Pact on Extortion Alternative Cutoffs for Defining Competition

\begin{tabular}{|c|c|c|c|c|}
\hline & $50^{\text {th }}$ Percentile & $60^{t h}$ Percentile & $70^{\text {th }}$ Percentile & $8 \mathrm{o}^{\text {th }}$ Percentile \\
\hline & $\log ($ Extortion +1$)$ & $\log ($ Extortion +1$)$ & $\log ($ Extortion +1$)$ & $\log ($ Extortion +1$)$ \\
\hline \multirow{3}{*}{$\operatorname{NonAggr}_{t} \times$ Comp $_{d}$} & $0.181^{* *}$ & $0.265^{* * *}$ & $0.225^{* *}$ & $0.297^{* * *}$ \\
\hline & $(0.081)$ & $(0.074)$ & $(0.097)$ & $(0.084)$ \\
\hline & {$[0.077]$} & {$[0.071]$} & [0.079] & {$[0.093]$} \\
\hline Month-Year FEs & Yes & Yes & Yes & Yes \\
\hline Municipality FEs & Yes & Yes & Yes & Yes \\
\hline Route FEs & Yes & Yes & Yes & Yes \\
\hline Outcome Mean & 1.95 & 1.95 & 1.95 & 1.95 \\
\hline Adjusted R2 & 0.489 & 0.492 & 0.490 & 0.491 \\
\hline Observations & 2,314 & 2,314 & 2,314 & 2,314 \\
\hline
\end{tabular}

Notes: The unit of observation is a route-municipality-month. The outcome variable is the log of the amount of extortion paid in a route-municipality-month in dollars plus one. The sample period is $6 / 2015$ to $1 / 2018$. The sample is comprised of all municipality-routes visited by the firm during the sample period. Covariates include census municipality characteristics - literacy, educational attainment, employment - interacted with year. Standard errors clustered at the municipality level in parentheses and Conley (1999) standard errors calculated using a $100 \mathrm{~km}$ cut-off window with a 20-month temporal auto-correlation window are presented in brackets (Colella et al. 2019). ${ }^{*} p<0.10,{ }^{* *} p<0.05,{ }^{* * *} p<0.01$.

Table A-10

Effect of Nonaggression Pact on Extortion Continuous Measure of Competition

\begin{tabular}{|c|c|c|c|c|c|c|}
\hline & \multicolumn{6}{|c|}{ Outcome: $\log ($ Extortion +1$)$} \\
\hline & (1) & (2) & (3) & (4) & (5) & (6) \\
\hline $\operatorname{NonAggr}_{t} \times \mathrm{HHI}_{\mathrm{d}}$ & $\begin{array}{c}-1.079^{* * *} \\
(0.378) \\
{[0.368]}\end{array}$ & $\begin{array}{c}-1.430^{* * *} \\
(0.233) \\
{[0.394]}\end{array}$ & $\begin{array}{c}-0.878^{* *} \\
(0.339) \\
{[0.462]}\end{array}$ & $\begin{array}{c}{ }^{-1.071^{* * *}} \\
(0.379) \\
{[0.368]}\end{array}$ & $\begin{array}{c}-1.436^{* * *} \\
(0.237) \\
{[0.394]}\end{array}$ & $\begin{array}{c}-0.877^{* *} \\
(0.336) \\
{[0.461]}\end{array}$ \\
\hline PESS $_{\mathrm{dt}}$ & & & & $\begin{array}{c}-0.044 \\
(0.106) \\
{[0.080]}\end{array}$ & $\begin{array}{c}-0.134 \\
(0.113) \\
{[0.084]}\end{array}$ & $\begin{array}{c}-0.105 \\
(0.116) \\
{[0.085]}\end{array}$ \\
\hline Month-Year FEs & Yes & Yes & Yes & Yes & Yes & Yes \\
\hline Municipality FEs & Yes & No & No & Yes & No & No \\
\hline Route FEs & Yes & No & No & Yes & No & No \\
\hline Municipality-Route FEs & No & Yes & Yes & No & Yes & Yes \\
\hline Route-NonAggr $r_{t}$ FEs & No & No & Yes & No & No & Yes \\
\hline Outcome Mean & 1.95 & 1.96 & 1.96 & 1.95 & 1.96 & 1.96 \\
\hline Adjusted R2 & 0.491 & 0.643 & 0.645 & 0.490 & 0.644 & 0.646 \\
\hline Observations & 2,314 & 2,166 & 2,166 & 2,314 & 2,166 & 2,166 \\
\hline
\end{tabular}

Notes: The unit of observation is a route-municipality-month. The outcome variable is the log of the amount of extortion paid in a route-municipality-month in dollars plus one. The sample period is 6/2015 to $1 / 2018$. The sample is comprised of all municipality-routes visited by the firm during the sample period. $H H I_{d}$ is defined using the gang affiliation and location of homicides in El Salvador in the three years prior to the nonaggression pact. PESS $S_{d t}$ is an indicator variable equal to one if the municipality was part of Plan Secure El Salvador (PESS) at month $t$ and zero otherwise. Regressions drop "singleton" groups when including additional fixed effects (Correia 2015). Covariates include census municipality characteristics - literacy, educational attainment, employment - interacted with year. Standard errors clustered at the municipality level in parentheses and Conley (1999) standard errors calculated using a $100 \mathrm{~km}$ cut-off window with a 20-month temporal auto-correlation window are presented in brackets (Colella et al. 2019). ${ }^{*} p<0.10,{ }^{* *} p<0.05,{ }^{* *} p<0.01$. 
Table A-11

Effect of Nonaggression Pact on Extortion Alternative Specifications

\begin{tabular}{|c|c|c|c|c|}
\hline & \multicolumn{4}{|c|}{ Outcome: $\log ($ Extortion +1$)$} \\
\hline & \multicolumn{2}{|c|}{$\begin{array}{c}\text { Control for } \\
\text { Development Proxies }\end{array}$} & \multicolumn{2}{|c|}{$\begin{array}{l}\text { Municipalities without } \\
\text { Homicides in Control }\end{array}$} \\
\hline & (1) & (2) & (3) & (4) \\
\hline NonAggr $_{t} \times$ Comp $_{d}$ & $\begin{array}{l}0.221^{* *} \\
(0.096) \\
{[0.078]}\end{array}$ & $\begin{array}{l}0.230^{* *} \\
(0.090) \\
{[0.090]}\end{array}$ & $\begin{array}{l}0.236^{* * *} \\
(0.077) \\
{[0.068]}\end{array}$ & $\begin{array}{l}0.153^{*} \\
(0.087) \\
{[0.082]}\end{array}$ \\
\hline $\begin{array}{l}\text { Development Proxies } \\
\text { Month-Year FEs } \\
\text { Municipality FEs } \\
\text { Route FEs } \\
\text { Municipality-Route FEs } \\
\text { Route-NonAggr } r_{t} \text { FEs }\end{array}$ & $\begin{array}{l}\text { Yes } \\
\text { Yes } \\
\text { Yes } \\
\text { Yes } \\
\text { No } \\
\text { No }\end{array}$ & $\begin{array}{l}\text { Yes } \\
\text { No } \\
\text { No } \\
\text { No } \\
\text { Yes } \\
\text { Yes }\end{array}$ & $\begin{array}{l}\text { No } \\
\text { Yes } \\
\text { Yes } \\
\text { Yes } \\
\text { No } \\
\text { No }\end{array}$ & $\begin{array}{l}\text { No } \\
\text { No } \\
\text { No } \\
\text { No } \\
\text { Yes } \\
\text { Yes }\end{array}$ \\
\hline $\begin{array}{l}\text { Outcome Mean } \\
\text { Adjusted R2 } \\
\text { Observations }\end{array}$ & $\begin{array}{c}1.95 \\
0.490 \\
2,314\end{array}$ & $\begin{array}{c}1.96 \\
0.645 \\
2,166\end{array}$ & $\begin{array}{c}1.92 \\
0.507 \\
2,458\end{array}$ & $\begin{array}{c}1.93 \\
0.653 \\
2,295\end{array}$ \\
\hline
\end{tabular}

Notes: The unit of observation is a route-municipality-month. The outcome variable is the $\log$ of the amount of extortion paid in a route-municipality-month in dollars plus one. The sample period is 6/2015 to $1 / 2018$. Development Proxies include annual municipalitylevel nightlight intensity and population density and census municipality characteristics interacted with year. The sample is comprised of all municipality-routes visited by the firm during the sample period. Standard errors clustered at the municipality level in parentheses and Conley (1999) standard errors calculated using a $100 \mathrm{~km}$ cut-off window with a 20-month temporal auto-correlation window are presented in brackets (Colella et al. 2019). ${ }^{*} p<0.10,{ }^{* *} p<0.05,{ }^{* * *} p<0.01$. 
Table A-12

Effect of Nonaggression Pact on Extortion Expanded Sample Period

\begin{tabular}{|c|c|c|c|c|c|c|}
\hline & \multicolumn{6}{|c|}{ Outcome: $\log ($ Extortion+1 $)$} \\
\hline & (1) & (2) & (3) & (4) & (5) & (6) \\
\hline & \multicolumn{6}{|c|}{ Panel A: Comp $p_{d}$ Using Homicide Composition } \\
\hline NonAggr $_{t} \times$ Comp $_{d}$ & $\begin{array}{c}0.217^{*} \\
(0.113) \\
{[0.078]}\end{array}$ & $\begin{array}{l}0.285^{* * *} \\
(0.085) \\
{[0.086]}\end{array}$ & $\begin{array}{l}0.192^{* *} \\
(0.083) \\
{[0.108]}\end{array}$ & $\begin{array}{c}0.214^{*} \\
(0.114) \\
{[0.079]}\end{array}$ & $\begin{array}{l}0.287^{* * *} \\
(0.086) \\
{[0.087]}\end{array}$ & $\begin{array}{c}0.193^{* *} \\
(0.085) \\
{[0.110]}\end{array}$ \\
\hline PESS $_{\mathrm{dt}}$ & & & & $\begin{array}{r}-0.039 \\
(0.100) \\
{[0.071]}\end{array}$ & $\begin{array}{r}-0.179 \\
(0.109) \\
{[0.072]}\end{array}$ & $\begin{array}{c}-0.164 \\
(0.112) \\
{[0.073]}\end{array}$ \\
\hline Month-Year FEs & Yes & Yes & Yes & Yes & Yes & Yes \\
\hline Municipality FEs & Yes & No & No & Yes & No & No \\
\hline Route FEs & Yes & No & No & Yes & No & No \\
\hline Municipality-Route FEs & No & Yes & Yes & No & Yes & Yes \\
\hline Route-NonAggr $\mathrm{f}_{\mathrm{t}}$ FEs & No & No & Yes & No & No & Yes \\
\hline Outcome Mean & 1.93 & 1.93 & 1.93 & 1.93 & 1.93 & 1.93 \\
\hline Adjusted R2 & 0.454 & 0.665 & 0.667 & 0.454 & 0.666 & 0.668 \\
\hline \multirow[t]{2}{*}{ Observations } & 6,593 & 6,187 & 6,187 & 6,593 & 6,187 & 6,187 \\
\hline & \multicolumn{6}{|c|}{ Panel B: Comp $p_{d}$ Using Inmate Composition } \\
\hline $\operatorname{NonAggr}_{t} \times$ Comp $_{d}$ & $\begin{array}{l}0.272^{* *} \\
(0.117) \\
{[0.083]}\end{array}$ & $\begin{array}{l}0.293^{* * *} \\
(0.077) \\
{[0.086]}\end{array}$ & $\begin{array}{l}0.262^{* * *} \\
(0.083) \\
{[0.112]}\end{array}$ & $\begin{array}{c}0.271^{* *} \\
(0.119) \\
{[0.084]}\end{array}$ & $\begin{array}{l}0.295^{* * *} \\
(0.080) \\
{[0.087]}\end{array}$ & $\begin{array}{l}0.264^{* * *} \\
(0.086) \\
{[0.114]}\end{array}$ \\
\hline PESS $_{\mathrm{dt}}$ & & & & $\begin{array}{c}-0.006 \\
(0.103) \\
{[0.072]}\end{array}$ & $\begin{array}{r}-0.179 \\
(0.113) \\
{[0.073]}\end{array}$ & $\begin{array}{c}-0.166 \\
(0.114) \\
{[0.073]}\end{array}$ \\
\hline Month-Year FEs & Yes & Yes & Yes & Yes & Yes & Yes \\
\hline Municipality FEs & Yes & No & No & Yes & No & No \\
\hline Route FEs & Yes & No & No & Yes & No & No \\
\hline Municipality-Route FEs & No & Yes & Yes & No & Yes & Yes \\
\hline Route-NonAggr FEs & No & No & Yes & No & No & Yes \\
\hline Outcome Mean & 1.93 & 1.94 & 1.94 & 1.93 & 1.94 & 1.94 \\
\hline Adjusted R2 & 0.459 & 0.666 & 0.668 & $0.45^{8}$ & 0.666 & 0.669 \\
\hline Observations & 6,390 & 6,017 & 6,017 & 6,390 & 6,017 & 6,017 \\
\hline
\end{tabular}

Notes: The unit of observation is a route-municipality-month. The outcome variable is the log of the amount of extortion paid in a route-municipality-month in dollars plus one. The sample period is March 2012 to March 2019. The sample is comprised of all municipality-routes visited by the firm during the sample period. In Panel A, Comp $p_{d}$ is defined using the gang affiliation and location of homicides in El Salvador in the three years prior to the nonaggression pact. In Panel B, Comp $p_{d}$ is defined using the gang affiliation and location of residence for inmates in El Salvador arrested in the three years prior to the nonaggression pact. For both, we construct an $H H I_{d}$ and define Comp $d$ as an indicator variable equal to zero if $H H I_{d}$ is in the top quartile of the HHI for municipalities and one otherwise. PESS $d t$ is an indicator variable equal to one if the municipality was part of Plan Secure El Salvador (PESS) at month $t$ and zero otherwise. Regressions drop "singleton" groups when including additional fixed effects (Correia 2015). Covariates include census municipality characteristics - literacy, educational attainment, employment - interacted with year. Standard errors clustered at the municipality level in parentheses and Conley (1999) standard errors calculated using a $100 \mathrm{~km}$ cut-off window with a 20-month temporal auto-correlation window are presented in brackets (Colella et al. 2019). ${ }^{*} p<0.10,{ }^{* *} p<0.05,{ }^{* * *} p<0.01$. 
Table A-13

Effect of Nonaggression Pact on Extortion Synthetic Difference-in-Difference Method

\begin{tabular}{|c|c|c|c|c|}
\hline & \multicolumn{4}{|c|}{ Outcome: $\log ($ Extortion +1$)$} \\
\hline & \multicolumn{2}{|c|}{ Standard DD } & \multicolumn{2}{|c|}{ Synthetic DD } \\
\hline & (1) & (2) & (3) & (4) \\
\hline NonAggr $_{t} \times$ Comp $_{d}$ & $\begin{array}{c}0.381^{* *} \\
(0.160)\end{array}$ & $\begin{array}{c}0.355^{* *} \\
(0.156)\end{array}$ & $\begin{array}{c}0.318^{* *} \\
(0.155)\end{array}$ & $\begin{array}{c}0.328^{* *} \\
(0.149)\end{array}$ \\
\hline Month-Year FEs & Yes & Yes & Yes & Yes \\
\hline Municipality-Route FEs & Yes & Yes & Yes & Yes \\
\hline Covariates & No & Yes & No & Yes \\
\hline Outcome Mean & 1.92 & 1.92 & 1.92 & 1.92 \\
\hline Observations & 3,132 & 3,132 & 3,132 & 3,132 \\
\hline
\end{tabular}

Notes: The unit of observation is a route-municipality-month. The outcome variable is the log of the amount of extortion paid in a route-municipalitymonth in dollars plus one. The sample period is $6 / 2015$ to $1 / 2018$. The results use the synthetic difference-in-difference approach from Arkhangelsky et al. (2021). The approach requires a balanced panel, therefore we fill in extortion for route-municipality-month without sales or extortion using surrounding months. Specification (1) and (2) show the results using this balanced panel using a standard DiD approach. Specification (3) and (4) use the jackknife procedure from Arkhangelsky et al. (2021) clustering at the municipality-route level. ${ }^{*} p<0.10,{ }^{* *} p<0.05,{ }^{* * *} p<0.01$.

Table A-14

Effect of Nonaggression Pact on Homicides Alternative Periods for Defining Competition

\begin{tabular}{|c|c|c|}
\hline & $\begin{array}{l}\text { HHI Defined } \\
\text { 1-4 Years Prior }\end{array}$ & $\begin{array}{l}\text { HHI Defined } \\
\text { 1-6 Years Prior }\end{array}$ \\
\hline & (1) & (2) \\
\hline NonAggr $_{t} \times$ Comp $_{d}$ & $\begin{array}{c}-0.315^{* *} \\
(0.149) \\
{[0.143]}\end{array}$ & $\begin{array}{c}-0.311^{* *} \\
(0.148) \\
{[0.143]}\end{array}$ \\
\hline Municipality FEs & Yes & Yes \\
\hline Month-Year FEs & Yes & Yes \\
\hline Outcome Mean & 0.94 & 0.89 \\
\hline Observations & 3,391 & 3,679 \\
\hline Clusters & 124 & 137 \\
\hline
\end{tabular}

Notes: The unit of observation is a municipality-month. Outcome is number of homicides in which MS-13 or Barrio 18 was a perpetrator or victim. The first two columns define the gang HHI measure using homicides over 4/1/2012 to 4/1/2015 while the last two columns use 4/1/2010 to 4/1/2015. Results from Poisson regressions. Municipalities in which the outcome is zero for all periods are dropped. Standard errors clustered at the municipality level in parentheses and Conley (1999) standard errors calculated using a $100 \mathrm{~km}$ cut-off window are presented in brackets. ${ }^{*} p<0.10,{ }^{* *} p<0.05,{ }^{* * *} p<0.01$. 
Table A-15

Effect of Nonaggression Pact on Extortion using Gang Competition Defined at Canton Level

\begin{tabular}{lcccccc}
\hline & \multicolumn{5}{c}{ Outcome: $\log ($ Extortion+1) } \\
\cline { 2 - 7 } & $(1)$ & $(2)$ & $(3)$ & $(4)$ & $(5)$ & $(6)$ \\
\hline NonAggr $_{\mathrm{t}} \times$ Comp $_{\mathrm{d}}$ & 0.175 & $0.180^{* *}$ & $0.225^{* *}$ & 0.165 & $0.183^{* *}$ & $0.222^{* *}$ \\
& $(0.124)$ & $(0.075)$ & $(0.105)$ & $(0.123)$ & $(0.077)$ & $(0.108)$ \\
& {$[0.095]$} & {$[0.077]$} & {$[0.102]$} & {$[0.096]$} & {$[0.078]$} & {$[0.104]$} \\
PESS $_{\mathrm{dt}}$ & & & & -0.153 & -0.142 & -0.166 \\
& & & & $(0.118)$ & $(0.142)$ & $(0.127)$ \\
& & & {$[0.085]$} & {$[0.097]$} & {$[0.092]$} \\
Canton FEs & Yes & No & No & Yes & No & No \\
Month-Year FEs & Yes & No & No & Yes & No & No \\
Route FEs & Yes & No & No & Yes & No & No \\
Canton-Route FEs & No & Yes & Yes & No & Yes & Yes \\
Route-NonAggrt FEs & No & No & Yes & No & No & Yes \\
\hline Outcome Mean & 1.99 & 2.01 & 2.01 & 1.99 & 2.01 & 2.01 \\
Adjusted R2 & 0.484 & 0.617 & 0.622 & 0.485 & 0.618 & 0.623 \\
Observations & 1,935 & 1,849 & 1,844 & 1,935 & 1,849 & 1,844 \\
\hline
\end{tabular}

Notes: The unit of observation is a route-canton-month. The outcome variable is the log of the amount of extortion paid in a route-canton-month in dollars plus one. The sample period is 9/2014 to $1 / 2018$. The sample is comprised of all canton-routes visited by the firm during the sample period. $P E S S_{d t}$ is an indicator variable equal to one if the municipality was part of Plan Secure El Salvador (PESS) at month $t$ and zero otherwise. Regressions drop "singleton" groups when including additional fixed effects (Correia 2015). Standard errors clustered at the canton level in parentheses and Conley (1999) standard errors calculated using a $100 \mathrm{~km}$ cut-off window with a 20-month temporal auto-correlation window are presented in brackets (Colella et al. 2019). ${ }^{*} p<0.10,{ }^{* *} p<0.05$, ${ }^{* *}$ $p<0.01$.

Table A-16

Effect of Nonaggression Pact on Hospital Visits Individual Diagnosis Categories

\begin{tabular}{lcccc}
\hline & $\begin{array}{c}\text { Diabetes } \\
\text { Diagnosis } \\
(1)\end{array}$ & $\begin{array}{c}\text { Hypertension } \\
\text { Diagnosis } \\
(2)\end{array}$ & $\begin{array}{c}\text { Coronary } \\
\text { Diagnosis } \\
(3)\end{array}$ & $\begin{array}{c}\text { Respiratory } \\
\text { Diagnosis } \\
(4)\end{array}$ \\
\hline NonAggr $_{\mathrm{t}} \times$ Comp $_{\mathrm{d}}$ & $0.119^{* * *}$ & 0.016 & 0.076 & $0.120^{*}$ \\
& $(0.031)$ & $(0.058)$ & $(0.068)$ & $(0.069)$ \\
& {$[0.035]$} & {$[0.040]$} & {$[0.042]$} & {$[0.078]$} \\
Municipality FEs & Yes & Yes & Yes & Yes \\
Month-Year FEs & Yes & Yes & Yes & Yes \\
\hline Outcome Mean & 1.72 & 4.69 & 1.34 & 1.72 \\
Observations & 4,588 & 4,588 & 4,557 & 4,557 \\
Clusters & 148 & 148 & 147 & 147 \\
\hline
\end{tabular}

Notes: Results from Poisson regressions in which the outcome is the number of visits in a municipality-month. Covariates include PESS and census municipality characteristics interacted with year. Standard errors clustered at the municipality level in parentheses and spatial standard errors calculated using a $100 \mathrm{~km}$ cut-off window are presented in brackets (Bertanha and Moser 2016). ${ }^{*} p<0.10,{ }^{* *} p<0.05,{ }^{* * *} p<0.01$. 
Figure A-9

Effect of Nonaggression Pact on Drug Prices and Associated Visits Dynamic Effects

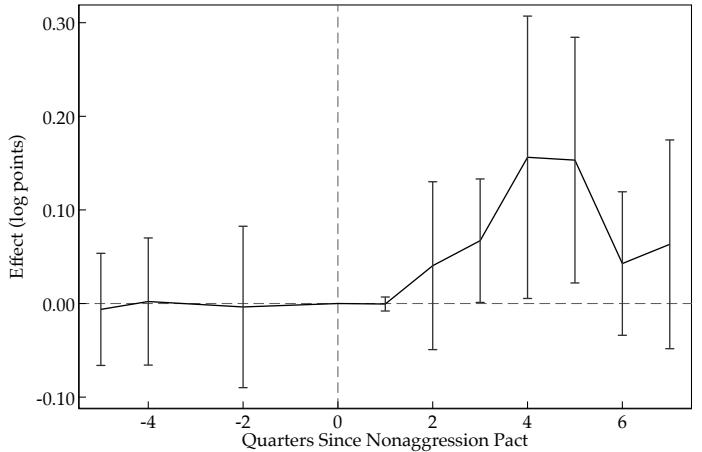

Panel A. Drug Prices

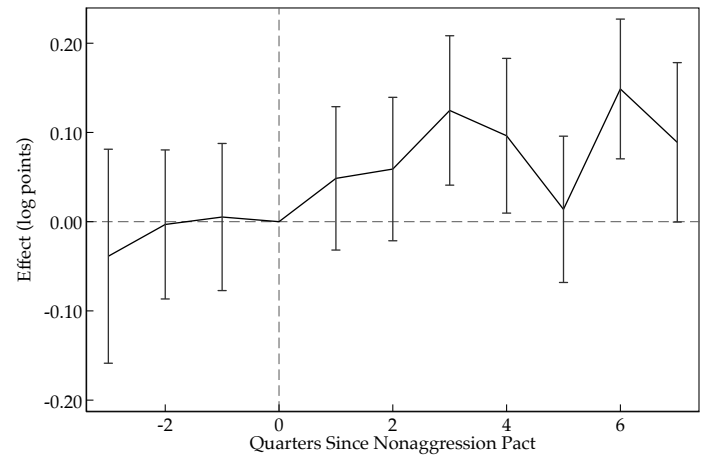

Panel B. Hospital Visits

Notes: Shows point estimates for each period using the difference-in-difference model. Panel A shows the effect on pharmaceutical prices. Panel B shows the effect on hospital visits for chronic conditions affected by drug adherence. The omitted period is the quarter prior to the start of the nonaggression pact between MS-13 and Barrio 18. Standard errors are clustered at the municipality level. All specifications include municipality fixed effects, month fixed effects, and controls for PESS and census municipality characteristics interacted with year. Error bars indicate $95 \%$ confidence intervals using standard errors clustered at the municipality level.

Table A-17

Effect of Nonaggression Pact on the Number of Pharmacies in Municipalities with Gang Competition

\begin{tabular}{lcc}
\hline & $\begin{array}{c}\text { Total Number } \\
\text { of Pharmacies }\end{array}$ & $\begin{array}{c}\text { Number of Pharmacies that } \\
\text { purchase from Distributor }\end{array}$ \\
\hline NonAggr $_{\mathrm{t}} \times$ Comp $_{\mathrm{d}}$ & 0.002 & -0.051 \\
& $(0.012)$ & $(0.044)$ \\
Municipality FEs & Yes & Yes \\
Year FEs & Yes & Yes \\
Covariates & Yes & Yes \\
\hline Outcome Mean & 13.81 & 6.62 \\
Observations & 3,540 & 2,201 \\
\hline
\end{tabular}

Notes: Results from Poisson regressions where the unit of observation is a municipality-month. In first column, the outcome is the number of pharmacies that are operating in a municipality-month obtained from pharmacy registration data. In the second column, the outcome is the number of pharmacies in a municipality-month in the distributor sales data. All specifications control for PESS and census municipality characteristics interacted with year. The sample period is $6 / 2015$ to $1 / 2018$. Standard errors clustered at the municipality level in parentheses. ${ }^{*} p<0.10,{ }^{* *} p<0.05,{ }^{* * *} p<0.01$. 


\section{Appendix References}

Asmann, Parker, "El Salvador Citizen Security Plan Struggling to Reduce Insecurity," 2018. InSight Crime.

Beck, Paul J and Michael W Maher, "A Comparison of Bribery and Bidding in Thin Markets," Economics letters, 1986, 20 (1), 1-5.

Dirección General de Estadística y Censos, "VI Censo de Población y V de Vivienda 2007," 2007. El Salvador Ministerio de Economía.

Ditta, Elise, "El Salvador Gang Leaders Order End to Killing," 2016. InSight Crime Brief.

Dudley, Steven, Héctor Silva Ávalos, and Juan José Martínez, "MS-13 in the Americas: How the World's Most Notorious Gang Defies Logic, Resist Destruction," InSight Crime, 2018.

Gambetta, Diego, The Sicilian Mafia: The Business of Private Protection, Harvard University Press, 1996.

_ , "Codes of the Underworld," in "Codes of the Underworld," Princeton University Press, 2011.

Global Initiative Against Transnational Organized Crime and InSight Crime, "A Criminal Culture: Extortion in Central America," 2019.

Lohmuller, Michael, “El Salvador Moves to Clamp Down on Prisons, Gangs," 2016. InSight Crime.

_ , "Reality Belies El Salvador Govt Rhetoric on 'Extraordinary Measures'," 2018. InSight Crime.

Lui, Francis T, “An Equilibrium Queuing Model of Bribery," Journal of political economy, 1985, 93 (4), 760-781.

Martínez, Óscar, Efren Lemus, Carlos Martínez, and Deborah Sontag, "Killers on a Shoestring: Inside the Gangs of El Salvador," The New York Times, 2016.

National Oceanic and Atmospheric Administration, "VIIRS Day/Night Band Nighttime Lights," 2020. Earth Observation Group, NOAA National Centers for Environmental Information (NCEI).

Neu, Dean, "Accounting for Extortion," Accounting, Organizations and Society, 2019, 76 (C), 50-63.

Olken, Benjamin A and Patrick Barron, "The Simple Economics of Extortion: Evidence from Trucking in Aceh," Journal of Political Economy, 2009, 117 (3), 417-452.

Olson, Mancur, "Dictatorship, Democracy, and Development," American political science review, 1993, 87 (3), 567-576.

Ponce, Carlos, "Street Corner Decisions: An Empirical Investigation of Extortionist Choices in El Salvador," Global Crime, 2021, 22 (2), 143-165.

Spengler, Joseph J, "Vertical Integration and Antitrust Policy," Journal of Political Economy, 1950, 58 (4), 347-352.

Tilly, Charles, War Making and State Making as Organized Crime, Routledge, 2017.

Varese, Federico, Sally Stein, and Allan Sekula, The Russian Mafia: Private Protection in a new market economy, Oxford University Press, 2005.

Wang, Peng, "The rise of the Red Mafia in China: a case study of organised crime and corruption in Chongqing," Trends in Organized crime, 2013, 16 (1), 49-73.

WorldPop, "The Spatial Distribution of Population, El Salvador," 2020. WorldPop and Center for International Earth Science Information Network (CIESIN), Columbia University. Global High Resolution Population Denominators Project. 